\title{
Alternative Approaches for the Determination of Unconfined Rock Deformation and Strength Properties
}

\author{
Thomas Stoxreiter $^{1} \cdot$ Paul Gehwolf $^{1} \cdot$ Robert Galler $^{1}$
}

Received: 29 March 2019 / Accepted: 6 July 2019 / Published online: 27 July 2019

(c) The Author(s) 2019

\begin{abstract}
The usage of numerical simulation tools in rock engineering has been the undisputed state of the art for decades. Not only for rock engineering applications in the field of underground and surface stability analysis, but also for the simulation of the rock-cutting process. With increasing computing capacity and as a consequence thereof, increased capabilities of available constitutive laws, the determination of reliable input parameters is critical. The detailed characterization and implementation of stress-strain relations, including the hardening and softening regime, is a major task. While efficient guidelines and established procedures exist for compressive loading, the current state of the art for tensile loading in the majority of the cases is inadequate. Samples often fail invalidly, either due to poor preparation or due to the impact of undesired bending and torsional loading. For that reason, an innovative purely mechanical test setup is proposed in this article, which eliminates the identified confounding effects. Furthermore, an alternative procedure for the investigation of rock dilatancy under unconfined conditions is presented. Although dilatancy is normally associated with multiaxial stress states and determined by triaxial compression tests, the behaviour of unconfined rock under far field compression represents an essential load case in rock cutting, but also in the surroundings of underground openings. The proposed procedure is based on torsion tests because of their capability to generate stress states of pure shear without exhibiting axial splitting and related negative effects. With the help of numerical simulations, a reasonable range for the dilatancy can be estimated and compared to common methods of determination via unconfined compression tests.
\end{abstract}

Keywords Dilatancy angle $\cdot$ Direct tension test $\cdot$ Torsion test $\cdot$ Numerical simulation

\section{Introduction}

The use of numerical simulation tools in rock mechanics has been the undisputed state of the art for decades. With increasing capacity and as a consequence thereof increased complexity of available constitutive laws, the determination of reliable input parameters is of great importance. Without including the various other methods currently available, the focus of this article is on finite-element analysis, which implicitly indicates a continuum mechanics approach. In depth, knowledge about the stress-strain curve for a wide range of loading situations is crucial to create realistic results from simulations. The two major aspects in this article deal with the stress-strain relations for tensile

Thomas Stoxreiter

thomas.stoxreiter@unileoben.ac.at

1 Montanuniversität Leoben, Erzherzog Johann Straße 3, 8700 Leoben, Austria loading and an alternative approach for the investigation of rock dilatancy for unconfined conditions. The concept of dilation was first introduced by Reynolds (1885) as the change of volume due to the change of shape or distortional strain. Subsequently, the phenomenon and effects of dilation were extensively investigated in the field of soil mechanics, important achievements were gained among others by Rowe (1962) and Roscoe (1970). Nearly, at the same time, pioneering work on rock dilation was performed by Brace et al. (1966) and Cook (1970). In the subsequent decades, a number of comprehensive and detailed studies about the treatment of the dilatancy angle in rock mechanics, including historical developments and state of the art methods, were performed. Some of the renowned contributions were provided by Alejano and Alonso (2005), Zhao and Cai (2010), Walton and Diederichs (2015) and others, who established different models to integrate the dilatancy angle into practical rock engineering. Basically, confining pressure and effective plastic strain dependence of the dilatancy angle 
are approved facts. Therefore, the authors will not expand further on this topic in general, but on particular aspects related to the current article. Remarkably, the majority of past approaches were more or less based on the fundamental work of Vermeer and De Borst (1984), who defined a mathematical formulation for the calculation of the dilatancy angle for loose and cemented granular materials. Soil or rock elements under consideration were assumed to be macroscopic and large enough to contain many particles as micro-elements. Their solution is based on non-associated plasticity theory with all its assumptions and restrictions as well as experimental data from triaxial compression tests and direct shear tests of various types of soil and rock. Bolton (1986) derived a similar solution for the computation of the dilatancy angle.

Vermeer and De Borst (1984) recommend focusing attention on the pre-peak hardening behaviour, since the postfailure softening behaviour of soil, rock and concrete, as shown for example by Rudnicki and Rice (1975) or Gerstle et al. (1980), is not objective due to non-uniformity of the strain over the specimen and the associated size effects. Bazant (1976) additionally emphasizes the influence of geometric boundary conditions related to grain size and sample dimensions for a mathematical treatment of strain-softening of concrete. Although the smeared strain measurement in uniaxial and triaxial compression tests over the entire specimen is not ideal, the relatively insensitive ratio of volumetric strain to axial strain increments can be adequately determined. However, this requires the volumetric strains to be measured via the amount of displaced fluid from the pressure cell. For unconfined but also triaxial compression tests, the alternative technique is to measure strains directly at the specimen, via extensometers or strain gauges. Indeed, the results are distorted by slabbing/splitting in the post-failure region and the occurrence of shear bands and bifurcation. Bifurcation results in the separation of the specimen into two, more or less, rigid bodies, causing severe impairment of the calculation of volumetric strains by measuring axial and lateral strains directly at the specimen. Consequently, the dilatancy angle cannot be determined reliably and a comparison method to estimate the dilatancy angle is considered to be a worthwhile supplement to conventional methods.

Partly as a consequence of the described complexities, several researchers report inconclusive data for the dilatancy angle at different positions along the stress-strain curve. Alejano and Alonso (2005) and Zhao and Cai (2010) relate their calculated (negative) dilation angles to the concave shape of the stress strain curve, due to closure of micro cracks which cause rather inelastic than plastic strains. Arzua and Alejano (2013) even indicate a dilation angle of minus infinity for similar reasons and decide to only apply their concept in the post-failure region. However, Walton et al. (2014) and Kwasniewski and Rodríguez-Oitabén (2012) conclude in accordance with the fundamental work of Brace et al. (1966) and Martin and Chandler (1994), that predominately axial cracking occurs in loading direction at lower axial stress levels, causing inelastic lateral strains. Due to zero or very small plastic axial strains, their calculations lead to exceptionally high dilatancy angles of $90^{\circ}$ at the very beginning and still more than $80^{\circ}$ at the peak region. However, as demonstrated by Vermeer and De Borst (1984), the theoretical maximum value for the dilatancy angle is limited by the friction angle. Considering that both properties are not constant but mobilized by straining and that the peak friction angle is reached at low damage, it is reasonable to assume that the dilatancy angle is mobilized in a similar manner. In any case, the maximum possible value for the dilatancy angle is the peak friction angle, which hardly exceeds $65^{\circ}$. The computed high dilatancy angles were related to the applied definition of plastic strains. Obviously, at least two types of inelastic strain occur, namely, crack closure and axial splitting, which are not caused by shear distortion. In combination with the fact that axial splitting is mainly caused by tensile failure at material heterogeneities, these inelastic strains must not be used in the calculation of the dilatancy angle. An interesting approach to solve this issue is presented by Walton and Diederichs (2015), who attempt to separate true plastic strains from other inelastic strains, dependent on a user-defined yield stress and constant elastic parameters. Nevertheless, Vermeer and De Borst (1984) verify that the dilatancy angle gradually increases to a limit dilatancy angle, which is nearly constant at and close to the peak region, but still distinctly smaller than the angle of friction, normally $20^{\circ}$ less. This conclusion is based on sound theoretical and experimental evidence, but is in contrast to the suggestions of Alejano and Alonso (2005) and Walton et al. (2015) to set the dilatancy angle for unconfined conditions equal to the friction angle for modelling purposes. Regarding these inconclusive results, an alternative method to investigate dilatancy under unconfined conditions up to the ultimate strength of the material was developed. An important constraint was the requirement that confounding effects such as crack closure and axial splitting should not affect the results.

This alternative method is based on an inverse determination procedure. Two series of torsion tests with one sedimentary rock (Imberg sandstone) and one crystalline rock (Neuhauser granite) were performed. The rock specimens were hourglass shaped and equipped with strain gauges with three measurement directions $\left(0^{\circ} / 45^{\circ} / 90^{\circ}\right)$ and also additional axial strain gauges. In addition, a video extensometer, measuring the axial strains contactless, was used. The inverse procedure exploits the fact that torsional loading generates pure shear stresses at the cylindrical middle section of the sample, causing plastic volumetric strains to occur as consequence of rock dilatancy. Thus, in contrast 
to a non-dilatant material, considerable axial strains occur during rock testing and the magnitude of these axial strains is directly related to the dilatancy angle. Furthermore, serious overestimation of the dilatancy angle, due to inelastic strains caused by axial splitting and crack closure, is avoided because of the overall low stress level and the stress state of pure shear. Pure shear stress directly implies an average normal stress of zero for elastic material behaviour. To estimate the associated dilatancy angle, the finite-element software package Abaqus 6.13 was used to model the experiments numerically. To enable a reasonable estimation of the dilatancy angle, a precise model of the experimental setup in combination with an appropriate constitutive model was required. The Concrete Damaged Plasticity model (CDP model), providing a general capability for modelling concrete and other quasi-brittle materials, was used as constitutive law and will be described in more detail in the next chapter. Simulations with various dilatancy angles were performed and based on the conformity between numerical and experimental results, a range for the dilatancy angle could be estimated. Obviously, only a range of ca. $\pm 5^{\circ}$ for the dilatancy angle can be expected from this procedure. However, concerning the general accuracy related to data for rock and rock mass, an estimation of the dilatancy angle to ca. $\pm 5^{\circ}$ is deemed as adequate. Already, a verification whether the dilatancy angle for unconfined loading is close to the friction angle or distinctly below is a highly relevant information. Furthermore, to the author's knowledge, this is the first application of torsion tests on rock at atmospheric pressure and one of the few ever performed. Paterson and Olgaard (2000) also conducted torsion tests on rock, but at high confining pressures and with the purpose to study the deformation behaviour in the Earth's crust.

Not only was the dilatancy angle investigated but also the tensile strength and stress-strain characteristics for tensile loading. The situation is quite different for the determination of the entire stress-strain curve for intact rock in uniaxial tension and compression. Based on the fundamental work of Wawersik and Fairhurst (1969), Rummel and Fairhurst (1970) and Wawersik and Brace (1970), procedures to reliably determine nearly the entire stress-strain curve in compression exist. Following the ISRM suggested methods (Fairhurst and Hudson 1999), unconfined compression tests were conducted reaching far in the post-failure locus. Several unloading-reloading cycles were performed to quantify the introduced damage by evaluating the degradation of the secant modulus along the post-failure curve. These tests enabled also the calculation of the dilatancy angle in the established form as a comparative measure to the outcome of the torsion experiments. However, the maximum compressive stress during the torsion experiments was rather low, not even exceeding $20 \%$ of the unconfined compressive strength; therefore, rock damage or failure in compression was insignificant. For uniaxial tension loading, the situation is completely different. The complete stress-strain curve, including post-failure data, is actually a highly relevant information for many constitutive models, but no method could be found yet to experimentally determine the postfailure behaviour of brittle rock in uniaxial tension. The low tensile strength of common rock types requires high standards on the test setup, and the fixation of the sample in the testing machine is much more complex than for compression tests. Despite following the valuable ISRM suggested methods for determining the direct tensile strength of rocks (Bieniawski and Hawkes 2007), samples often fail invalidly, either due to poor preparation or the impact of undesired bending and torsional loading. Therefore, an improved test setup, operating purely mechanically, was developed by the Chair of Subsurface Engineering together with Sandvik Mining and Construction G.m.b.H and the Institute of Physics at the Montanuniversität Leoben. In combination with an optimized specimen geometry, reliable and repeatable results for the rock mechanical behaviour under uniaxial tensile loading could be achieved up to failure. The method and the differences to the state of the art methodology are presented in this article.

\section{Theory}

\subsection{Dilatancy Angle and Concrete Damaged Plasticity Model}

In accordance with the definition of dilatancy as the change in volume associated with shear distortion of an element in the material, the dilatancy angle $\psi$ defines the ratio of plastic volume change over plastic shear strain. Vermeer and De Borst (1984) present the mathematical framework to calculate the dilatancy angle from triaxial tests data. Therefore, the authors will not extend on the derivation of the subsequent equations, which are considered the most relevant equations for the current article, but reference to the original paper. However, Eq. (1) is actually exactly valid only for simple shear and gives the best meaning for the dilatancy angle:

$\sin \psi=\frac{\dot{\varepsilon}_{v}^{p}}{\dot{\gamma}^{p}}$.

The plastic volumetric strain rate is $\dot{\varepsilon}_{v}^{p}$ and $\dot{\gamma}^{p}$ is the rate of plastic distortion. To enable another form of presentation, Vermeer and De Borst (1984) made use of the following definition of $\dot{\gamma}^{p}$ to derive Eq. (3), where $\dot{\varepsilon}_{i}^{p}$ with $i=1,2,3$ are the principal plastic strain rates:

$\dot{\gamma}^{p}=\left|\dot{\varepsilon}_{3}^{p}-\dot{\varepsilon}_{1}^{p}\right|$ 
Equation (3) can be simply derived by assuming plane strain conditions, by applying Eq. (2) and the common definition of plastic volumetric strains as the sum of the plastic principal strains. For plane strain, the component $\dot{\varepsilon}_{2}^{p}$ has to be zero. Equation (1) can then be rewritten in form of Eq. (3), which forms the basis for almost all calculations of the dilatancy angle by other researchers. Vermeer and De Borst (1984) prove that Eq. (3) is also valid for three-dimensional stress states in common triaxial testing:

$\sin \psi=-\frac{\dot{\varepsilon}_{v}^{p} / \dot{\varepsilon}_{1}^{p}}{2-\dot{\varepsilon}_{v}^{p} / \dot{\varepsilon}_{1}^{p}}$.

The model proposed by Lubliner et al. (1989) forms together with the modifications suggested by Lee and Fenves (1998) the basis for the Concrete Damaged Plasticity model. The dilatancy angle is in that respect defined according to the stress-dilatancy equation of Rowe (1972). As shown by Vermeer and De Borst (1984), both definitions blend into each other and are commonly used to introduce hardening behaviour via the mobilized friction angle and the mobilized dilatancy angle. In other words, the experimental evidence of the variation of soil parameters with plastic strain and confining pressure is considered. However, a partly different approach is pursued for the implementation of the dilatancy angle in the CDP model by the finite-element software Abaqus 6.13. By definition, the model is primarily intended to provide a general capability for the analysis of concrete structures, but is also suitable for the analysis of other quasi-brittle materials, such as rock, mortar, and ceramics. The constitutive relations capture the effects of irreversible damage associated with the failure mechanisms that occur in quasi-brittle materials under confining pressures up to five times the ultimate compressive stress. To incorporate the dependency of the plastic strain components on confining pressure, a hyperbolic Drucker-Prager flow rule is used, stated via Eq. (4) and illustrated in Fig. 1c (Dassault Systèmes 2013). Input parameters include the dilatancy angle $\psi_{\mathrm{CDP}}$ and the eccentricity $\varepsilon$, which defines the rate at which the function approaches the asymptote (straight line). Hence, the dilatancy angle is not constant, but changes with the value of $\varepsilon$, as observable in Fig. 1c. For low eccentricity values, the dilatancy angle $\psi_{\mathrm{CDP}}$ remains more or less constant over a wide range of confining pressure, and with increasing values for $\varepsilon$, the confining pressure dependence of $\psi_{\mathrm{CDP}}$ increases as well. However, in the CDP constitutive model, the dilatancy angle is defined slightly different to the common definition given by Vermeer and De Borst (1984). Equation (5) shows the formulation applied in the CDP model and Eq. (6) shows the simple way of conversion to the common definition, given in Eqs. (1) or (3). Equation (5) was actually derived for the linear Drucker-Prager flow rule by Jiang and Wu (2012), but is also valid for the hyperbolic flow rule. Definitions for
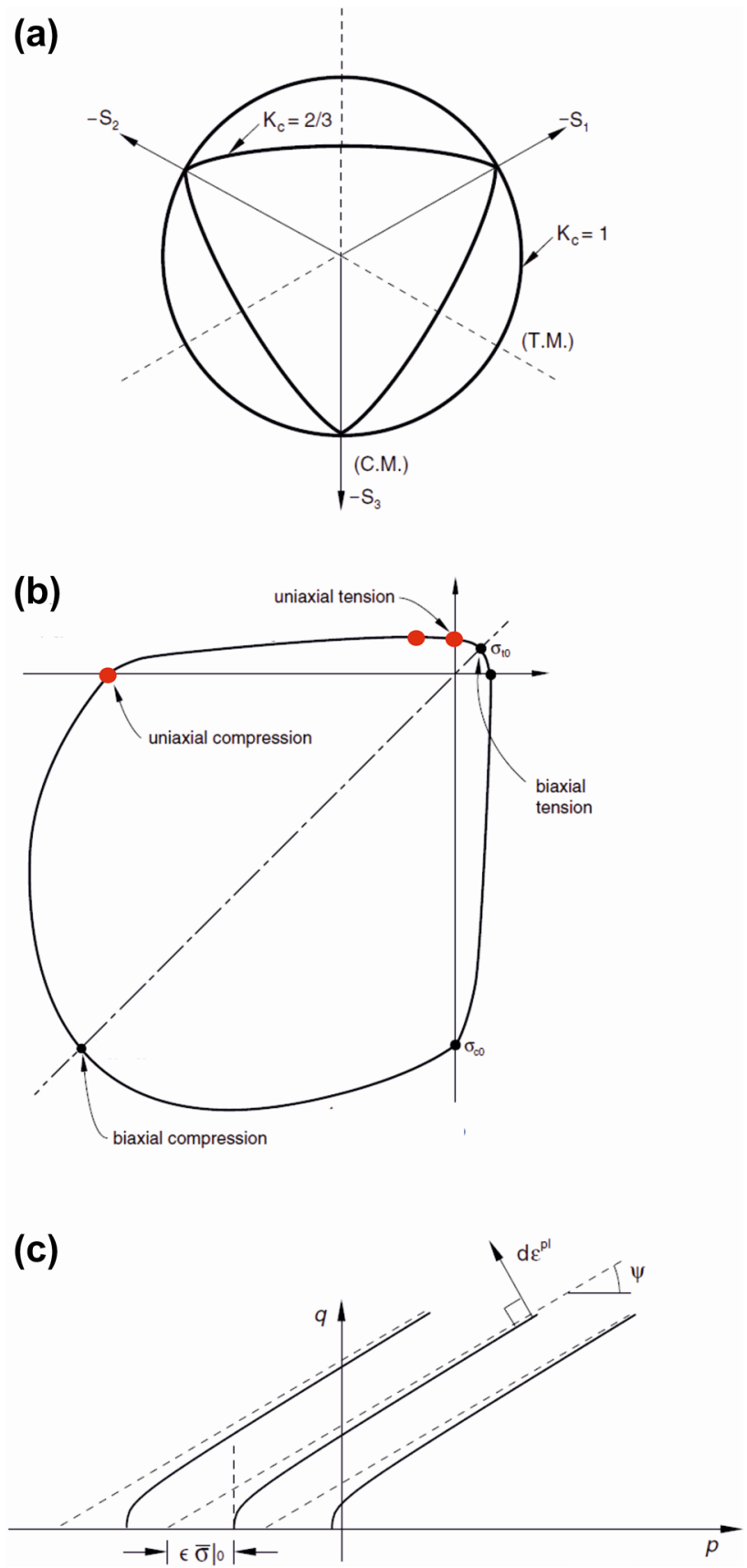

Fig. 1 Yield surfaces in the deviatoric plane, corresponding to different values of $K_{\mathrm{c}}(\mathbf{a})$, yield surface in plane stress (b) and several hyperbolic Drucker-Prager flow potentials in the $p-q$ plane (c) (Dassault Systèmes 2013)

the hydrostatic stress $\bar{p}$ and the von Mises equivalent effective stress $\bar{\sigma}$ are given in Eqs. (7) and (8):

$$
\begin{aligned}
& G=\sqrt{\left(\in \sigma_{t 0} \tan \psi_{\mathrm{CDP}}\right)^{2}+\bar{q}^{2}}-\bar{p} \tan \psi \\
& \tan \psi_{\mathrm{CDP}}=\frac{3 \dot{\varepsilon}_{v}^{p}}{2 \dot{\gamma}^{p}}
\end{aligned}
$$


$\psi=\arcsin \left(\frac{2}{3} \tan \psi_{\mathrm{CDP}}\right)$

$\bar{p}=-\frac{\bar{\sigma}_{1}+\bar{\sigma}_{2}+\bar{\sigma}_{3}}{3}$

$\bar{q}^{2}=\left[\left(\bar{\sigma}-\bar{\sigma}_{2}\right)^{2}+\left(\bar{\sigma}_{2}-\bar{\sigma}_{3}\right)^{2}+\left(\bar{\sigma}_{3}-\bar{\sigma}_{1}\right)^{2}\right]$.

$\overline{\boldsymbol{\sigma}}=\frac{\boldsymbol{\sigma}}{1-d}$.

The model uses concepts of isotropic damaged elasticity in combination with isotropic tensile and compressive plasticity to represent the inelastic behaviour of concrete. Following established definitions by Gross and Seelig (2017), isotropic damage implies that defects have no preferential direction considering their spatial distribution; thus, the state of damage can be described simply by a scalar damage variable $d$, for tension $d_{\mathrm{t}}$ and compression $d_{\mathrm{c}}$, which are assumed to be functions of the plastic strain in tension $\varepsilon_{\mathrm{t}}^{\mathrm{pl}}$ and compression $\varepsilon_{\mathrm{c}}^{\mathrm{pl}}$ and may have values between 0.0 (undamaged) and 1.0 (fully damaged). The relation between the Cauchy stress tensor $\boldsymbol{\sigma}$ and the effective stress tensor $\overline{\boldsymbol{\sigma}}$ is provided via Eq. (9). Softening behaviour in tension as opposed to initial hardening followed by softening in compression is implemented features, see Fig. 2. The shape of the yield function is primary based on the initial uniaxial tensile yield stress $\sigma_{\mathrm{t} 0}$, initial uniaxial $\sigma_{\mathrm{c} 0}$ and equibiaxial $\sigma_{\mathrm{b} 0}$ compressive yield stress, the ultimate uniaxial compressive stress $\sigma_{\mathrm{cu}}$ (UCS), and a constant form factor $K_{\mathrm{c}}$, which depends on the ratio of the second deviator invariant of the tensile meridian and compressive meridian. According to Lubliner et al. (1989), straight meridians can be reasonably assumed and, therefore, constant values for $K_{\mathrm{c}}$ as well. In Fig. 1, the yield surface and the plastic potential are displayed in different stress spaces, where the dependence of the shape of the yield surface in the deviator plan on the magnitude of $K_{\mathrm{c}}$ is clearly visible in Fig. 1a. The difference between an ordinary Drucker-Prager yield surface $\left(K_{\mathrm{c}}=1\right)$ is obvious.

Utilization of isotropic damage concepts requires obviously a fine discretization to minimize direction dependence of the results. An indirect method to determine the magnitude of damage is to measure the degradation of the elastic stiffness with increasing plastic strain by performing a sufficient number of unloading-reloading cycles during testing, for compression as well as for tension, since the results are expected to be different. The elastic constants of initial secant modulus $E_{0}$ and Poisson's ratio are required input parameters for the virgin state. The described correlations are displayed in Fig. 2 for uniaxial compression and tension, and experimental stress-strain curves are directly
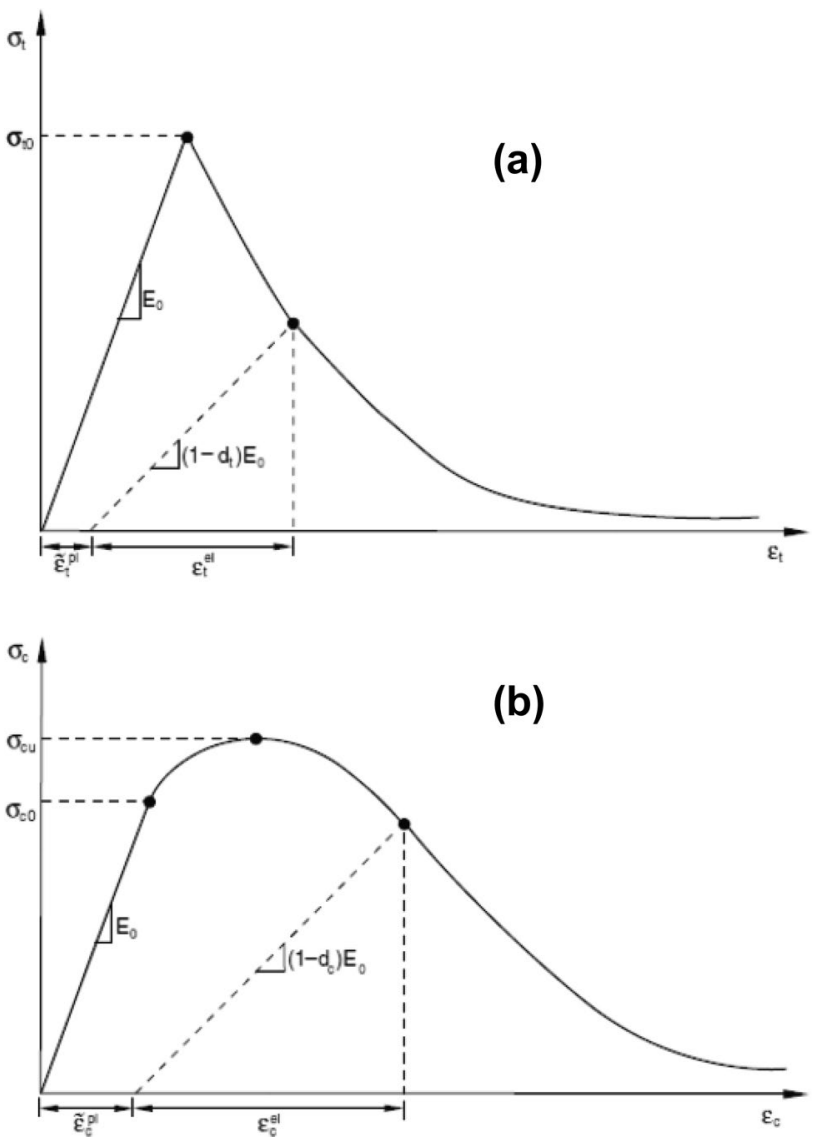

Fig. 2 Response of concrete to uniaxial loading in tension (a) and compression (b) (Dassault Systèmes 2013)

implemented in tabular form in the constitutive model. Consequently, the magnitude of the plastic strain components depends not only on the dilatancy angle, but also on the damage behaviour. The determination procedure for the input parameters will be presented in a later chapter. For more general and detailed information about capabilities and limitations of the constitutive model, the authors reference to the comprehensive manuals provided by the supplier of the software.

\subsection{Determination of Rock Behaviour due to Tensile Loading}

The reliable determination of the stress-strain behaviour of rock under tension is an indispensable component of the input parameters not only for the CDP model, but also for other higher order constitutive models. Although the experimental implementation is related to several difficulties, the low tensile strength of rock requires high standards for the test setup and the clamping of the sample into the testing machine, which is far more complex than for compression testing. Due to the difficult realization of uniaxial tensile 
tests in the past, several indirect methods and correlations to related rock mechanical parameters were frequently used to estimate the direct tensile strength (Perras and Diederichs 2014). However, even if these methods allow a reasonable estimation of the direct tensile strength, the entire stress-strain curve cannot be derived. Hence, direct tensile tests are unavoidable if the true stress-strain characteristics, at least up to the ultimate strength level, are required. Mellor and Hawkes (1971) presented two test methods to measure the tensile strength by diametrical compression of solid discs and annulus/hoops. These tests where solid discs are used are better known as Brazilian tests and are very common in the field of rock engineering. Provided the material shows linear-elastic behaviour until failure, the stress field throughout the disc can be accurately calculated analytically. According to Mellor and Hawkes (1971), the Brazilian test leads in reality to a biaxial stress field, rather than a uniaxial stress field. The second test which was mentioned requires samples in the form of a hoop and also diametrical compression. For the ring test, a steep stress gradient occurs, which leads to a small volume of material being critically stressed.

Broch and Franklin (1972) proposed a method to reduce the number of unconfined compression tests via the point load test (Missouri Highway and Transport Department 1981). Garner (1961) observed during his analysis of the rock cutting process with drill bit inserts that rupture of the sample occurred due to tensile failure. Hence, this test could also be used to indirectly estimate the tensile strength as an index parameter. In the field of petroleum engineering, hydraulic fracturing tests, e.g., according to Haimson (1968) or Hubbert and Willis (1957), are widely used. Zoback et al. (1977) conducted laboratory tests to identify the influence of the fluid penetration on the results using intact and prefractured rock. Due to penetration of the sample or existing micro cracks, the stress level which leads to failure during hydraulic fracture tests might be unknown and the influence on the test results cannot be estimated. Comparability is only achieved by empirical methods. A method preventing penetration of the fluid was developed by Singh (1974), using a sleeve-fracturing device (dilatometer) in the form of a flexible tube inserted into the bored hole. Despite the variety of available indirect testing methods for the determination of the tensile strength, a general major drawback is the assumption of linear-elastic material behaviour up to peak strength. Rock material seldom shows linear stress-strain relations up to the peak value. Therefore, indirect tests are not ideally qualified to define input parameters for higher order constitutive models and might, therefore, only be used as index values (Mellor and Hawkes 1971).

Accordingly, direct tensile tests need to be performed to gain sufficient information about the stress-strain relations. Subsequently, the state-of-the-art testing methods and their possible shortcomings are presented to explain why the development of an improved testing procedure was required for the current purpose. Hawkes and Mellor (1969) released a summary of the different methods of tensile tests for rock, which differ with respect to sample shape, attachment of the sample and connection with the loading frame. Grosvenor (1961) proposed cylindrical specimens and mechanical clamping, while Obert et al. (1946) fixed the specimen with cement into metal collars. Grosvenor (1961) suggested also to cast the specimen into collars, but with different materials. Gradually, the method of gluing or casting cylindrical samples into metal caps was established and is nowadays part of the suggested methods for rock characterization of the international society of rock mechanics (Bieniawski and Hawkes 2007). The distinct disadvantage of cylindrical specimens is that location and stress level of rupture are influenced by the fixation of the specimens, which often fail at the fixing point before reaching the true uniaxial tensile strength. In addition, bending and torsion-free fixation in the pulling system has to be ensured. This is mostly realized with flexible connectors such as cables or chains, which results in significantly reduced stiffness of the testing equipment and thus a deteriorated quality of test run control. Alternatively, Blümel (2000) developed the modified tension test (MTT), using a cylindrical sample, which is over cored from the top and from the bottom by two axial core holes with different diameters. Loading is applied on one side with a load plate and on the other with a load ring in a testing machine for compressive testing. Failure occurs by reaching the tensile strength in the area between the overlapping drill holes. With this testing method, the uniaxial tensile strength can be determined, but not the stress-strain behaviour. Finally, no adequate technique was found to derive stress-strain curves, ensuring bending and torsion-free fixation of the sample in combination with a high stiffness of the loading frame and straightforward implementation into common laboratory equipment.

\section{Experimental Setup and Results}

\subsection{Rock Type Description}

The direct tension tests as well as the torsion tests were performed with the same types of rock, where both show very homogenous grain size distribution. The crystalline rock was termed Neuhauser granite and is an intrusive rock of the Bohemian Massif, fine to medium grained with predominant mineral phases: quartz, feldspar, and biotite, see Fig. 6. The samples were extracted from a quarry in Upper Austria. The second rock type was a sedimentary rock, termed Imberg sandstone, originating from a quarry close to Dortmund, Germany. Predominant mineral phases are quartz, carbonates, feldspar, and muscovite. Besides the rock mechanical 
testing methods under consideration in the current article, many tests were performed by the Chair of Subsurface Engineering on both types of rock, including uniaxial compression tests (UCT), uniaxial tension tests (UTT) according to ISRM, triaxial compression tests (TCT), wedge splitting tests (WST), and Brazilian tests (BT). From the long testing history, it appears possible that the properties of Imberg sandstone vary, depending on the location of mining (mainly depth) in the quarry in a certain range. Hence, the input parameters for the numerical simulation were defined only by results from experiments, where the specimens were drilled out of the same block of rock as the torsion and tension test specimens. In addition, results from tests performed in the last 5 years are illustrated in Table 1, where BTS is the Brazilian tensile strength. The totality of all performed Brazilian tests in the last 5 years shows a standard deviation of less than $15 \%$, and this is considered as usual natural variation. The virgin secant modulus was defined as stiffness in the mostly linear-elastic region between the end of the concave-up curve and crack damage stress (Martin and Chandler 1994). Different secant moduli were considered for tension and compression in the later evaluation because of experimental evidence. This is not only true for the currently tested rock types, but also for many rock types in general (Haimson and Tharp 1974; Sundaram and Corrales 1980; Stimpson and Chen 1993; Yu et al. 2005). The Poisson's ratio was estimated in the same region and was taken as a constant value. The reader might be a little surprised by the similar values of the UCS for granite and sandstone, but this observation is explained by the high degree of cementation and the poorly rounded grains of Imberg sandstone.

\subsection{Direct Tensile Test}

Caused by the different methods for the determination of the tensile strength with direct and indirect methods the results often exhibiting a wide range. Only with direct tensile tests, the true stress-strain characteristics can be defined. For indirect testing methods, a more or less accurate estimation of the uniaxial tensile strength is possible, without any information about the stress-strain curve. Based on the findings from direct tensile tests according to the suggested methods of ISRM (Bieniawski and Hawkes 2007) and the problems with fracture at the clamping position due to stress concentration (Franklin and Dusseault 1989), an improved testing concept was developed. Obvious differences to the ISRM suggested methods are the pure mechanical sample fixation and the shape of the rock specimen, as illustrated in Fig. 3.

\subsubsection{Experimental Setup}

Hoek (1964) proposed the use of non-cylindrical samples. Due to the state-of-the art machining technologies with computerized numerical control (CNC), it is nowadays possible to prepare rock samples with any shape. The use of dog bone-shaped samples for direct tensile tests is actually state of the art in many engineering disciplines, including concrete testing (Yoshitake et al. 2012; Moradian and Shekarchi 2016) and also rock testing (Gorski et al. 2007). The primary purpose normally is to improve the clamping area using simplified dog bone-shaped samples. Because of the resulting high stress gradients in the clamping area, dog bone-shaped specimens were replaced by a more or less hourglass-shaped geometry for the current experiments. The applied hourglass-shaped design was defined and optimized with the help of a finite-element analysis. Ensuring a uniaxial stress state with the greatest stress magnitude in the middle of the sample which forced rupture to localize in the middle part of the sample, therefore, precluding failure at the clamping position. Because of the cylindrical shape of the middle section, strain measurements with strain gauges were feasible similar to common cylindrical rock samples. The smallest diameter of the sample was $25 \mathrm{~mm}$, ca. 10 times the maximum measured grain size of Neuhauser granite, where the grain size varied between 0.25 and $2.5 \mathrm{~mm}$. For sandstone, this aspect poses obviously no critical issue, since the minimum sample diameter was more than 40 times the maximum grain size.

Using the presented concept, the time-consuming preparation work of cementing samples in metal caps was omitted. Furthermore, the cementation process constitutes a potential source of error in terms of misalignment. Although a bending and torsional moment-free linkage system is required by the ISRM-suggested methods, experimental evidence shows that this request is hardly feasible with state of the art-testing equipment. As a result, many rock samples fail close to the fixing points and/or show failure mechanisms related to bending and torsional stresses, leading to invalid results. To achieve reliable and repeatable results, the used fixation device was designed and manufactured at the Montanuniversitaet Leoben. Figure 3 illustrates the novel fixation device which could be easily installed in the
Table 1 Rock mechanical parameters of Neuhauser granite and Imberg sandstone

\begin{tabular}{lrrlll}
\hline Rock type & UCS, MPa & BTS, MPa & Density, kg/m & $\begin{array}{l}\text { Secant modulus } \\
\text { (compression), GPa }\end{array}$ & Poisson's ratio \\
\hline Neuhauser granite & $145 \pm 17.3$ & $9.7 \pm 0.7$ & 2650 & $62 \pm 7.8$ & 0.16 \\
Imberg sandstone & $145 \pm 15.5$ & $10.7 \pm 0.9$ & 2560 & $41 \pm 3.1$ & 0.16 \\
\hline
\end{tabular}



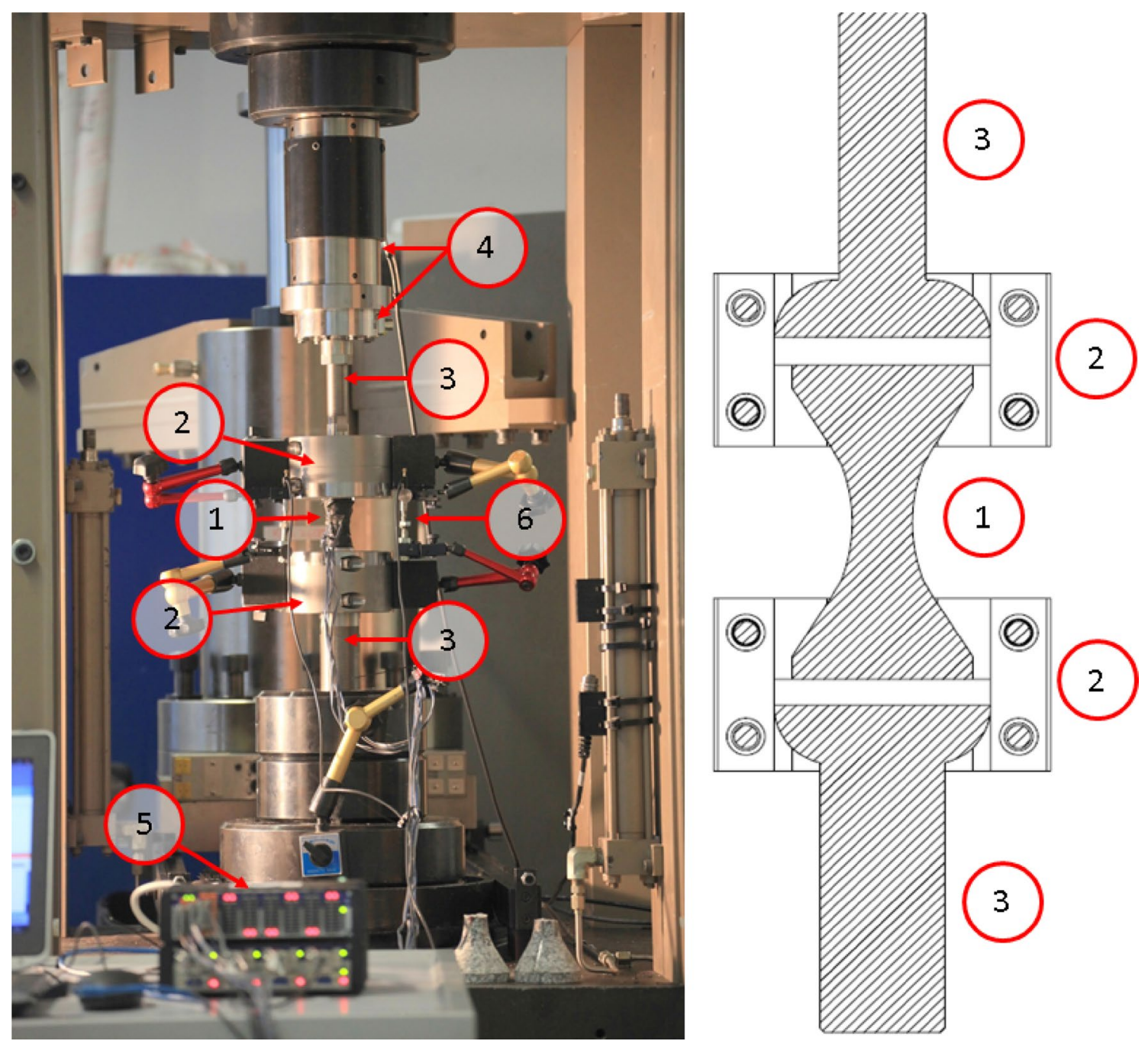

Fig. 3 Test setup for the novel tensile test with 1, hourglass-shaped sample; 2, sleeves; 3, connecting rod; 4, load cells; 5, measurement amplifiers; 6, LVDTs

available servo-hydraulic rock testing machine MTS 815 . This machine is characterized by a high frame stiffness and a modular setup, thus different experimental test rigs can be used. The basic features were as follows: the hourglassshaped sample (1) was mechanically clamped at both ends in the two sleeves (2) without gluing. The connection between the testing machine and fixation device was done via two connecting rods (3). To ensure bending and torsion-free fixation in combination with self-centering properties, the contact between sleeve and connecting rod was made with spherical ends. The glue-free connection guaranteed fast change of the samples between the test runs. Admittedly, the general testing effort was somewhat shifted from the sample installation to the specimen preparation. The rock specimens were prepared with high accuracy by a mason, using CNC technology. Clearly, higher costs for sample preparation need to be considered than for ordinary cylindrical-shaped samples. However, it is believed that the distinctly increased reliability and repeatability justify the increased costs. The force measurement was done with a redundant system of two load cells (4) with $25 \mathrm{kN}$ and $250 \mathrm{kN}$ measuring range. For the strain measurement, basically, four strain gauges with a measuring grid length of $6 \mathrm{~mm}$ were applied in the middle of the sample. The tests were carried out under displacement control with a defined rate of $0.05 \mathrm{~mm} / \mathrm{min}$. The servo-hydraulic rock press was controlled with a MTS FlexTest FT60 controller and for data acquisition the processed input signals were transferred to a universal measurement amplifier HBM QuantumX MX840A (5) as an analog signal. In addition, a measurement amplifier HBM QuantumX MX1615B (5) especially for strain gauges was used and both were time synchronised via FireWire. Two LVDTs HBM WI/2MM-T (6) were applied via a magnetic fixture to check the movement of the sleeves and ensure a pure axial 
movement without tilting. The data acquisition was done with a frequency of $300 \mathrm{~Hz}$ and the measured values were visualized on a computer and stored for post processing.

\subsubsection{Results}

All performed tests showed the expected fracture behaviour with one single tension crack at the reduced cross section of the sample perpendicular to the loading direction. Due to these observations, it was reasonably assumed that a pure tension failure occurred and the true tensile strength was determined. Figure 4 shows the mean value of the measured strain vs. the applied stress for the six tests conducted with Imberg sandstone. Furthermore, test results from direct tension tests according to ISRM, conducted at the Chair of Subsurface Engineering, are illustrated in Fig. 4. For reasons of clarity, the measurement results were piecewise linearized and the cutoff of the measured values was done at the maximum tensile stress, at which the tests were terminated anyway. Obviously, the simplification of linear-elastic material behaviour until failure is not valid for this type of sandstone. Up to a stress of ca. $3 \mathrm{MPa}$, all experiments showed linear elastic stress-strain relations and subsequently started to deviate distinctly from linear elastic behaviour, indicating increasing inelastic strains. Although the results for the ISRM compliant direct tension tests showed an acceptable scattering, the different test runs started to diversify at a relatively low stress level compared to the improved procedure, although the small grain size and homogenous structure of Imberg sandstone definitely constituted ideal testing properties. It is not really surprising that the results for Neuhauser granite yielded greater scattering concerning the maximum tensile strength. The deviation from linear behaviour occurred at the same stress level as for Imberg sandstone, approximately at $2.9 \mathrm{MPa}$. Rock specific reasons might have been the higher ratio of minimum sample diameter to maximum grain size, but also the petrographic nature of the granite. In contrast to the homogenous cement matrix of the sandstone, the strength was distinctly influenced by the bond strength of the mineral grains. Nevertheless, five out of eight of the ISRM compliant experiments showed an adequately narrow distribution, while the other three experiments differed from the observed behaviour. The results are illustrated in Fig. 5, where deviating test results are marked with a rectangle.

One might attribute these observations to natural scattering and consequently statistical methods might be used. However, if $5 / 8$ tests show a similar behaviour and $3 / 8$ tests show in principle the same behaviour, but fail at a much lower stress level, poor test conditions are the most probable explanation. Especially, as these effects were not observed during direct tensile tests with the proposed setup. Admittedly, also these experiments yielded a relatively high distribution, but still to a much less extent. A possible explanation for the scattering was the slight misalignment of single strain gauges and the therewith related measurement error. Another salient difference, especially for the experiments with granite, was the shape of the stress-strain curve. While the ISRM compliant experiments yielded only slightly non-linear behaviour, the current experiments showed distinct nonlinear stress-strain relations. This difference was most likely caused by the type and location of strain measurement. With the proposed test setup, the strains were measured with strain gauges along a distance of $6 \mathrm{~mm}$ at the location of maximum axial stress. In contrast, the strains at the ISRM compliant experiments were measured with extensometers with $50 \mathrm{~mm}$ measurement length. While for the strain gauges, the influence of single grains could have had an impact on the results, the long measurement distance of the extensometers led inevitably to a smeared measurement of strains at the location of strain
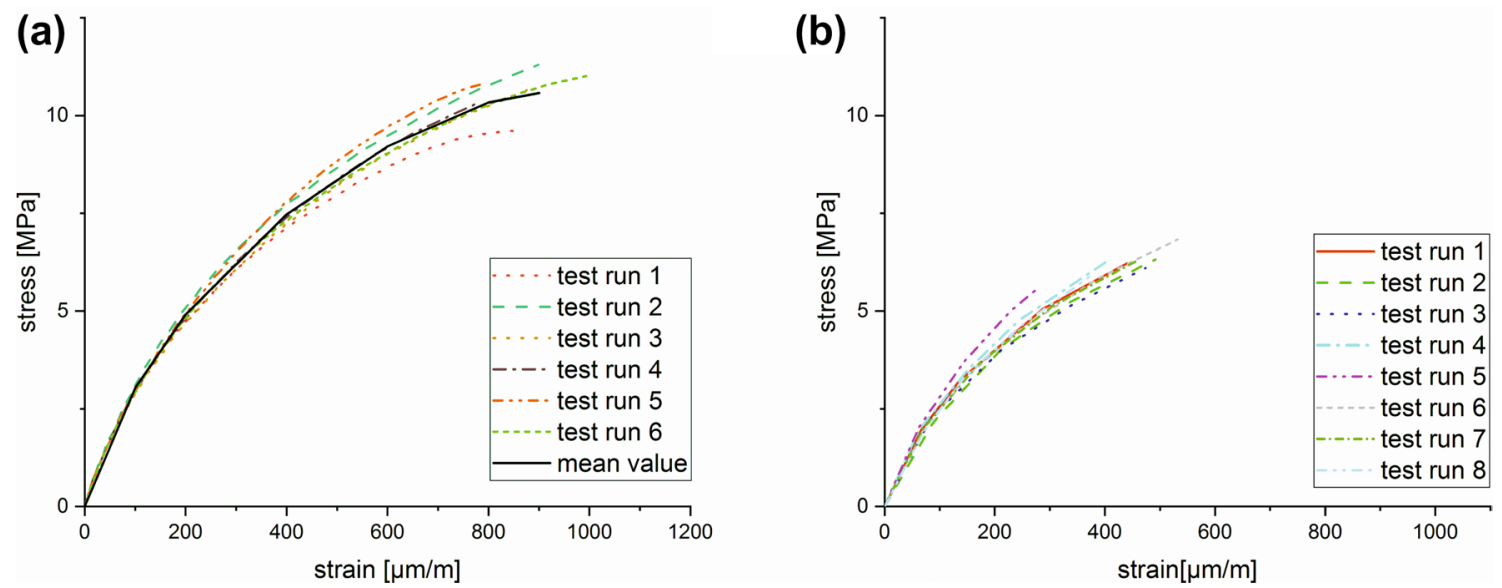

Fig. 4 Results for direct tension tests with Imberg sandstone for experiments with a proposed new test setup and $\mathbf{b}$ setup according to ISRM 

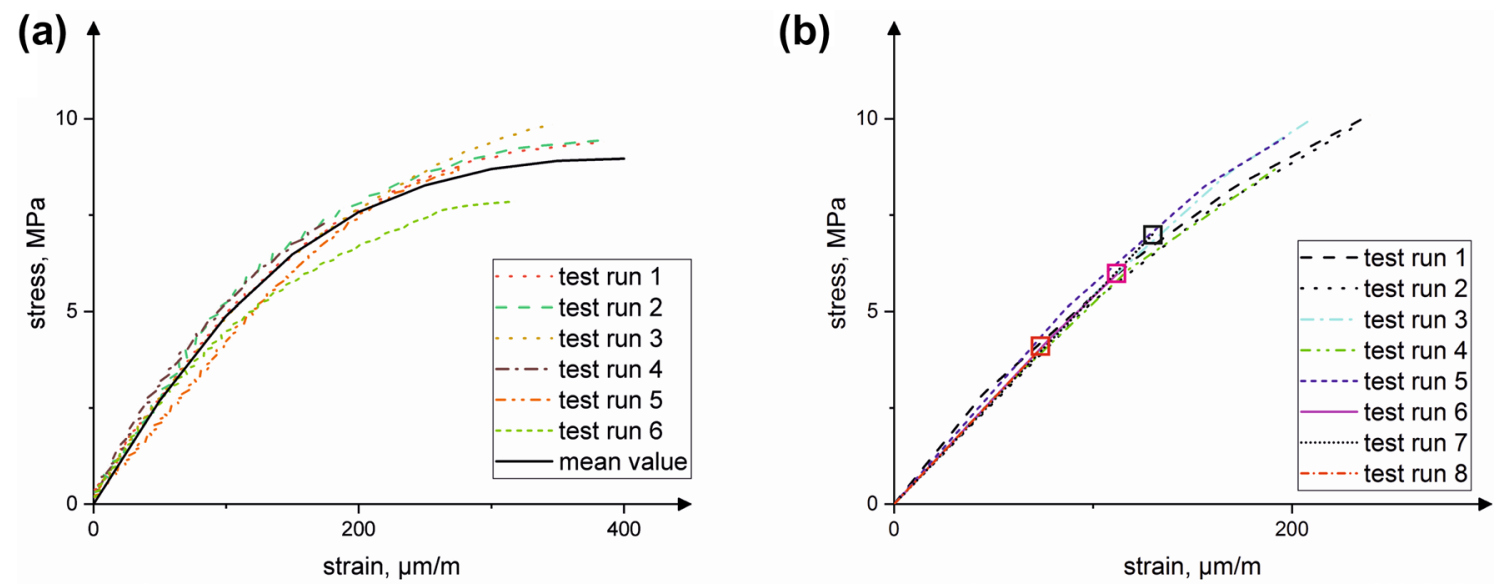

Fig. 5 Results for direct tension tests with Neuhauser granite for experiments with a proposed new test setup and $\mathbf{b}$ setup according to ISRM

localization and the associated strains in the neighbouring regions, as proposed by Hillerborg (1985). Comparing the secant modulus for uniaxial tension with the one for uniaxial compression, a significantly lower value was determined for tensile loading. The tensile secant modulus of Imberg sandstone was about $30.5 \mathrm{GPa}$ in contrast to $41.0 \mathrm{GPa}$ for compression. Similar results were found for Neuhauser granite with ca. 54.0 GPa for tensile loading and $62.0 \mathrm{GPa}$ for compression. All results are summarized in Table 2. In addition, the natural water content of the tested rock types was determined according to the ISRM suggested methods. Interestingly, the BTS and UTS were in good accordance for the proposed new setup for both rock types, but only for Neuhauser granite for the ISRM compliant experiments. The evaluation of the measurement results showed that all four strain gauges measured almost equal strain values, hence a bending-free clamping and fixation could be assumed. This impression was supported by location and type of rupture, exemplarily illustrated in Fig. 6. The results of the LVDT measurement are not considered for the test evaluation, because they simply showed the continuous re-arrangement of the clamping to ensure centric, bending-, and torsion-free loading and represent, therefore, not the behaviour of the rock itself.

\subsection{Torsion Test}

Torsion tests are commonly used for material characterisation purposes in the engineering industry. In general, hourglass-shaped samples are twisted and torque and torsion are measured. Furthermore, combined loading situations can be tested, see, for example, Zarroug et al. (2003). Because of the wide usage in other fields, the very first intention was to check the applicability for rock mechanical purposes. Rapidly, the idea was born to use torsion tests to estimate the dilatancy angle. Uncertainties related to the accurate determination of the occurring plastic volumetric strains and the plastic axial strains resulted in the concept to measure the total axial strains and apply an inverse determination procedure for the dilatancy angle by numerical simulations. Hence, the stress-strain curves derived from the direct tension tests were directly implemented in the evaluation of the torsion tests. As already described in the theory chapter, the characteristic stress-strain curves for uniaxial tension and compression are direct input parameters for the CDP model. For that reason, highly accurate and reliable results were required for both types of loading. However, this requirement is effectively appropriate for any numerical simulation with the purpose to describe the rock mechanical behaviour realistically, so actually, no additional effort was caused by the proposed method.
Table 2 Summarized results for direct tension tests

\begin{tabular}{llllllll}
\hline Experiment type & Rock type & $\begin{array}{l}\text { Num- } \\
\text { ber of } \\
\text { tests }\end{array}$ & $\begin{array}{l}\text { Tensile } \\
\text { strength, } \\
\text { MPa }\end{array}$ & $\begin{array}{l}\text { Mean } \\
\text { deviation, } \\
\text { MPa }\end{array}$ & $\begin{array}{l}\text { Mean } \\
\text { devia- } \\
\text { tion, } \%\end{array}$ & $\begin{array}{l}\text { Young's } \\
\text { modulus, } \\
\text { GPa }\end{array}$ & $\begin{array}{l}\text { Water } \\
\text { content, } \\
\%\end{array}$ \\
\hline ISRM compliant & Neuhauser granite & 10 & 8.61 & 1.48 & 17.2 & 56.2 & 0.12 \\
Proposed setup & Neuhauser granite & 6 & 8.79 & 0.82 & 9.3 & 53.9 & \\
ISRM compliant & Imberg sandstone & 8 & 6.20 & 0.26 & 4.2 & 28.7 & 0.24 \\
Proposed setup & Imberg sandstone & 6 & 10.62 & 0.43 & 4.0 & 30.4 & \\
\hline
\end{tabular}




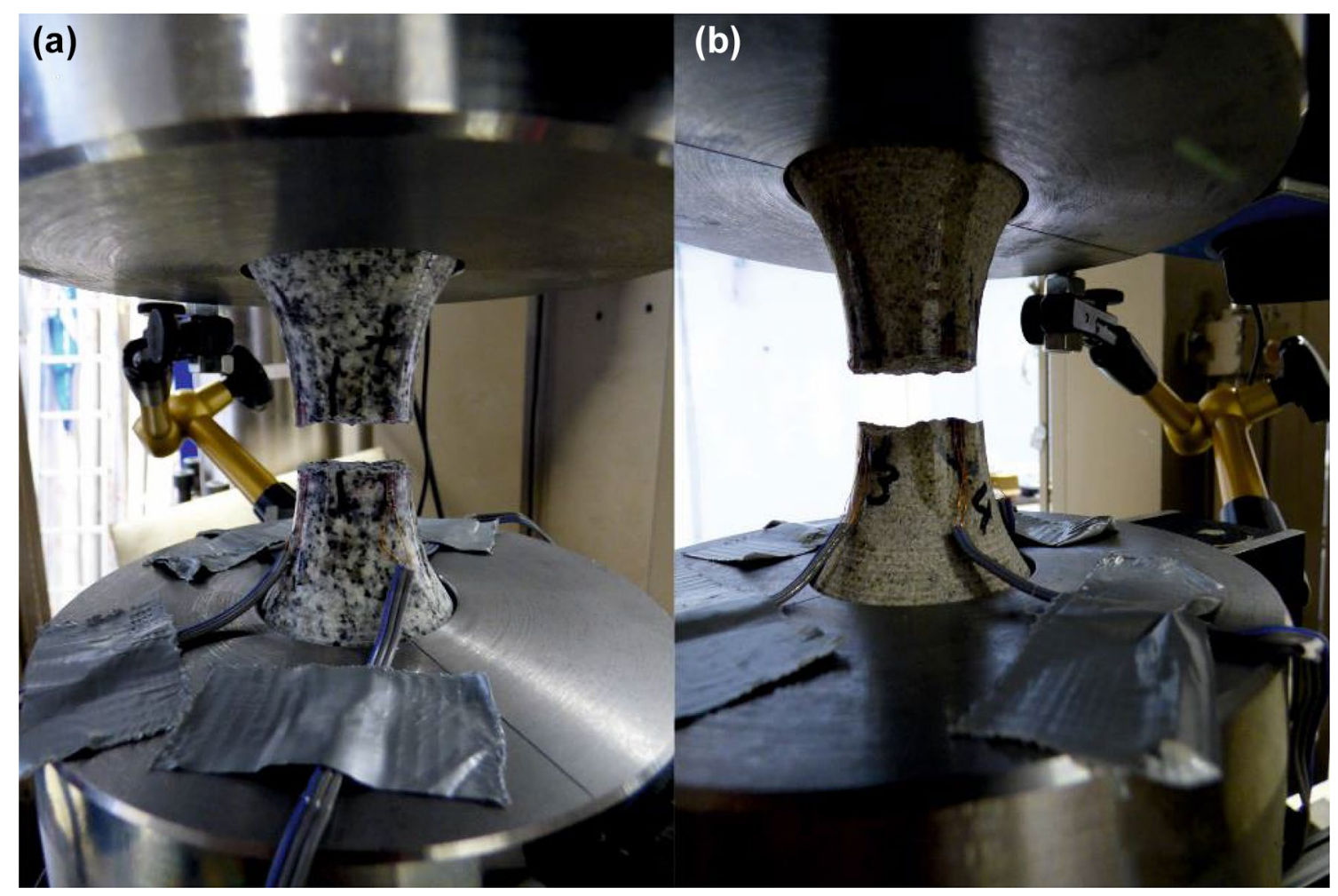

Fig. 6 Results of direct tension test $\mathbf{a}$ granite and $\mathbf{b}$ sandstone

\subsubsection{Experimental Setup}

As usual in the engineering industry, the samples used for the torsion tests had a reduced cross section in the middle of the sample to ensure stress concentration in this area. The geometry was based on common dimensions in metal or plastic testing and was optimized by numerical modelling. The minimum sample diameter was $26.5 \mathrm{~mm}$. The experiments were conducted at the Chair of Mechanical Engineering, Montanuniversitaet Leoben, using a test bench for static and dynamic pure torsion tests, as illustrated in Fig. 7. The basic test bench consisted of an electric motor, mounted behind the fixed bearing (1), a floating bearing (2) to ensure free axial expansion of the sample during the test and collet chucks (3) to fix the specimen. The torsional moment was measured by a HBM $1 \mathrm{kNm}$ torque sensor at the floating bearing side. To evaluate different measurement concepts, three different versions were applied. For the current test series, a video extensometer (4) from the company Messphysik Materials Testing $\mathrm{GmbH}$ was used to measure the axial displacement contactless over a length of approx. $75 \mathrm{~mm}$. The video extensometer needed to be calibrated to the actual distance to the rock specimen by a standardized procedure and remains in the same position throughout the tests. In addition, axial and rosette strain gauges (5) with a measuring grid length of $6 \mathrm{~mm}$ were mounted at the reduced cross section which had a nearly perfect cylindrical shape. Second, several experiments were conducted with three axial strain gauges without video extensometer, and as a third version, some experiments were conducted with the video extensometer measurement only. Sample shape and testing procedure remained the same for all tests. The applied loading rates varied between $0.03 \%$ and $0.07^{\circ} / \mathrm{s}$, which are common values for metal testing.

\subsubsection{Experimental Results}

Two test series of torsion tests on Imberg sandstone and Neuhauser granite were successfully conducted. Since the authors were not aware of any other results for torsion tests on rock under atmospheric conditions, no guidelines and recommendations were available. Therefore, a certain learning curve was necessary. The applied testing procedure and measurement methods were adequate; however, some shortcomings were identified. For the sandstone specimens, any type of measurement setup worked out very well, as illustrated in Fig. 8. The occurring strains were averaged for all strain gauges measuring in the same direction. For granite, the scattering of the video extensometer measurements was significant, see Fig. 9, where the strain gauges yielded more consistent results. However, for granite, the strain measurement was difficult due to the very small occurring 


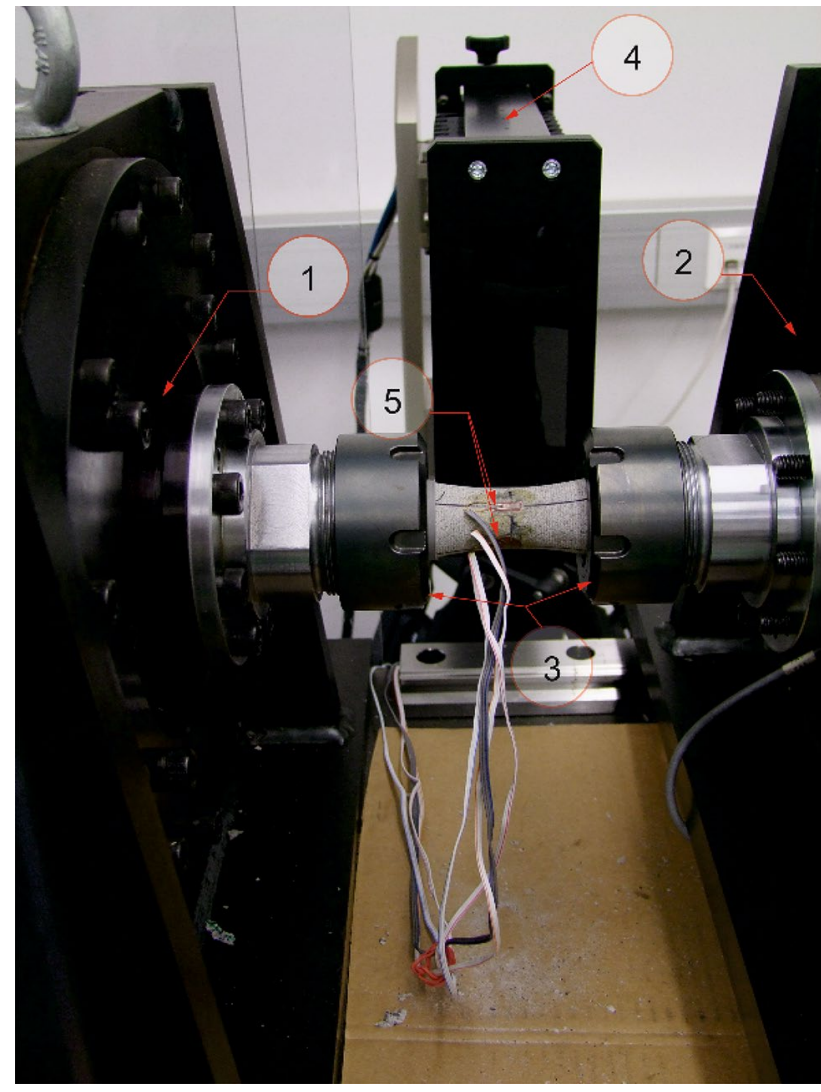

Fig. 7 Experimental setup for torsion test with a sandstone sample mounted and the components: 1, fixed bearing; 2 , floating bearing; 3 , collet chucks; 4 , video extensometer; 5 , strain gauges

strains; therefore, only the maximum torsional moment could be obtained for some experiments. As the distortion of the rock sample did not yield any significant impact on the strain gauge measurements, the measurement setup with three axial strain gauges and without video extensometer was preferred for granite testing. The results, displayed in Figs. 8 and 9, are a mixture of all three measurement setups; hence, curves with the same label for the video extensometer and for the strain gauge measurements were not necessarily from the same experiment. For Imberg sandstone, this fact is actually irrelevant, since all conducted experiments yield very similar results. Curves marked with * were terminated before failure, because the sample was slipping inside the collet chucks, identified by a constant torsional moment with increasing distortion. While collet chucks are a sufficient clamping device for metal samples, for rock testing, they appear to be not perfectly appropriate. Changes for future experiments could be expected using rectangular end sections at the sample and an appropriate seating. Due to this fact, no proper distortion vs. torsional moment curves or distortion vs. stress curves could be produced. The minimum diameter of the sample was identified as another point for potential improvement. Two samples broke already during installation in the testing machine. For the current testing setup the maximum diameter, and because of the defined shape also the minimum diameter, were limited by the maximum available size of the collet chucks. With rectangular end sections, this limitation could be removed.

The onset of plastic strains was detected by the over-proportional increase in axial strains, clearly visible in Figs. 8 and 9. Especially, the video extensometer measurements in Fig. 8b emphasize this observation. The magnitude of these occurring axial strains is directly related to the occurring volumetric strains and, therefore, also directly to the dilatancy angle. This statement is supported by the results of the numerical simulation. As shown in Fig. 12, a material with a dilatancy angle $\psi_{\mathrm{CDP}}$ of $0.1^{\circ}$ exhibits actually no axial strains, while an increasing dilatancy angle results in increasing axial strains. The threshold stress, which causes the axial strains to increase over-proportionally, could be
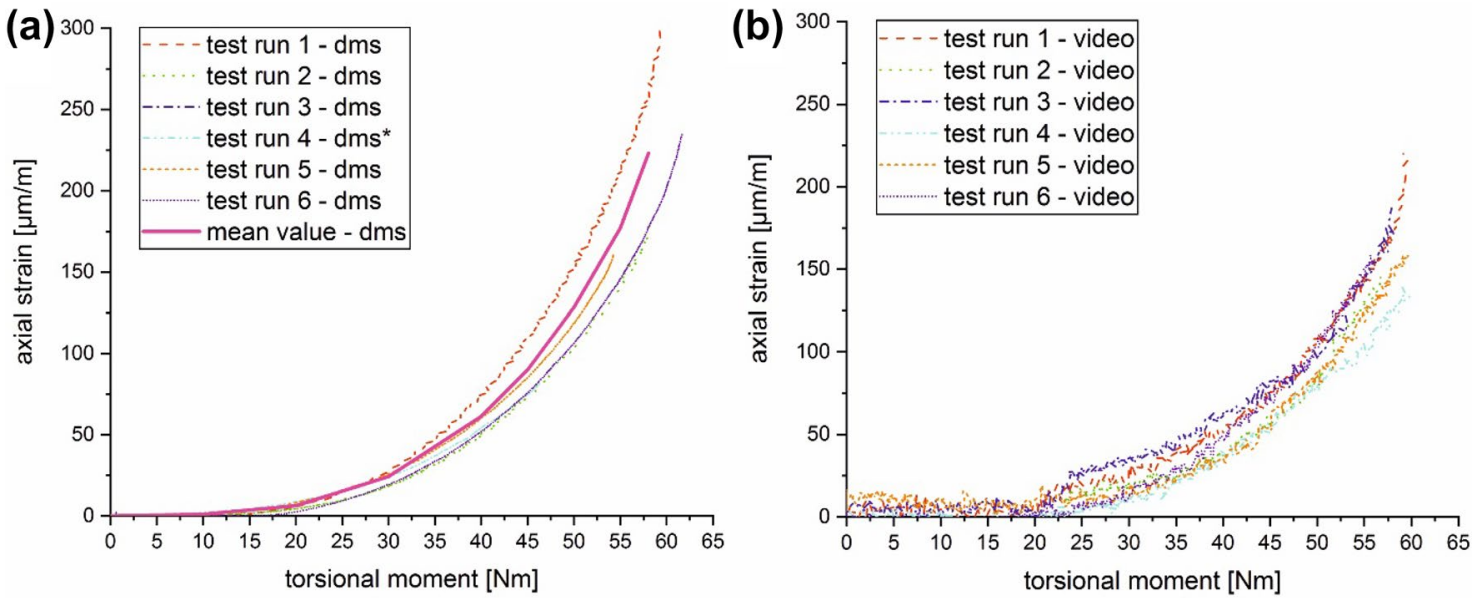

Fig. 8 Results of torsion tests with Imberg sandstone for strain measurement with a strain gauges and $\mathbf{b}$ video extensometer 

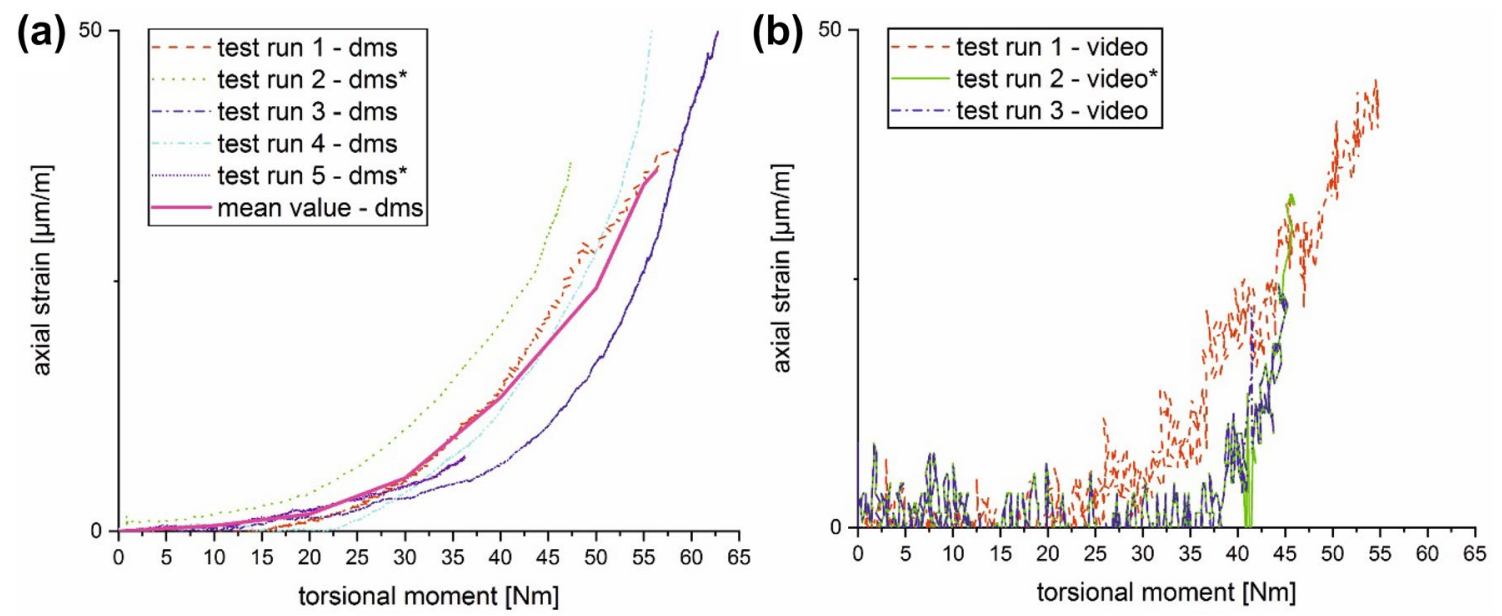

Fig. 9 Results of torsion tests with Neuhauser granite for strain measurement with a strain gauges and $\mathbf{b}$ video extensometer

identified by the numerical simulation as the stress, where inelastic strains first occur in the model. This threshold stress is in turn equivalent to the position at the tension stress-strain curve, where the material behaviour deviates from linear-elastic. For sandstone, the associated torsional moment in the experiments was different for the strain gauge-based and video extensometer-based measurement. This is because of the stress concentration at the middle section of the specimen with the minimum cross-sectional area, with a minimum section modulus, where the strain gauges were applied. In contrast, the video extensometer captured the strains over a distinctly larger distance with increasing cross-sectional area. Thus, the shear stresses reduced along the specimen because of the increasing section modulus. Hence, for the estimation of the shear stress at the middle of the specimen, the strain gauge measurement-based value of approx. $10 \mathrm{Nm}$ has to be used. This also applies for the experiments with Neuhauser granite. With the reasonable assumption of linear elastic behaviour up to this threshold stress level as described above, the shear stress $\tau$ was calculated with Eq. (10) at the cylindrical middle section of the specimen, where $M_{\mathrm{t}}$ is the torsional moment and $W_{\mathrm{p}}$ is the polar section modulus:

$\tau=\frac{M_{\mathrm{t}}}{W_{\mathrm{p}}}$

The associated shear stress for the onset of plastic strains was estimated to be around $2.75 \mathrm{MPa}$. Interestingly, Neuhauser granite yielded a similar value. Indeed, applying Eq. (10) implicitly assumes equivalent stiffness for tension and compression, which is not valid for the tested rock types, and therefore, the calculated values are not completely exact. Regarding the maximum torsional moment, both rock types resulted in very similar values as well, for Neuhauser granite
$54.6 \pm 6.8 \mathrm{Nm}$ and for Imberg sandstone $56.8 \pm 2.9 \mathrm{Nm}$. This observation can be explained by the type of failure. Figure 10 shows exemplarily two failed rock samples after torsional loading. Both samples failed in a direction of approx. $45^{\circ}$ to the specimen axis. This is the direction of maximum principal normal stresses in the elastic region. Although the direction of the maximum principal stresses rotates a little with plastic distortion, the deviation to $45^{\circ}$ should only be a few degrees. The obvious conclusion is that both rock types failed due to normal stress in tension. This result could be expected for brittle materials, but still had to be validated. Hence, there exists a direct relation between the stress-strain curve from the direct tension test and the torsional moment vs. axial strain curve from the torsion test. This fact became also apparent in the stress value for the onset of plastic strains. The torsional moment vs. axial strain curves constitute the basis for the later comparison of experimental and numerical results and the associated estimation of the dilatancy angle. Contrary to uniaxial compression tests or compression tests at low confining pressure, the results were not influenced by axial cracking or crack closure as described by Walton et al. (2014). First, because the axial strain gauges were placed in a direction of maximum shear stress and not in the direction of the principal normal stress as in compression testing. Second, the overall stress level was very low, so that no axial splitting due to compressive loading was observed. These features constitute, therefore, a major benefit to ordinary compression testing:

$\tau_{\mathrm{p}}=\frac{4}{3} \times \frac{M_{\mathrm{t}}}{W_{\mathrm{p}}}$.

The occurring maximum shear stress could be roughly estimated by assuming two boundary cases. The first case 


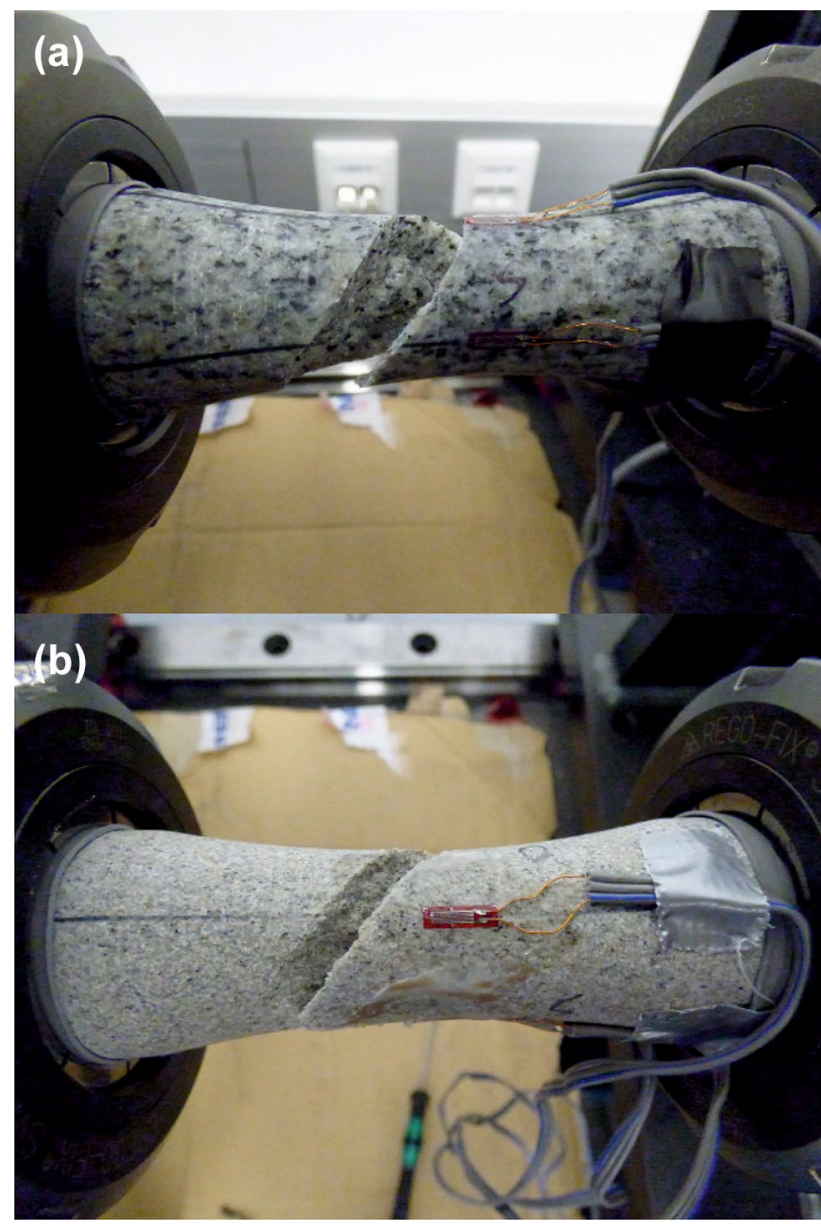

Fig. 10 Rock specimen after torsion testing with three axial strain gauges a Neuhauser granite and b Imberg sandstone

concerns total plastic behaviour for the entire cross-sectional area of the sample in a perfectly plastic manner. For a brittle material such as rock, this case is obviously unrealistic, but provides an upper limit for the ultimate load $\tau_{\mathrm{p}}$. The second case concerns purely elastic strains, which means that by reaching the yield stress, the ultimate load is reached as well. This case might be treated as a lower limit for the ultimate load if the reason for failure is shear stress and not normal stress. The two limit cases were calculated with Eqs. (10) and (11) given by Hibbeler (2006). Applying $56.8 \mathrm{Nm}$ for Imberg sandstone yields a maximum stress of $15.5 \mathrm{MPa}$ for the total plastic state, while the particular case of purely elastic strains until failure results in a stress of $11.6 \mathrm{MPa}$, so very close to the direct tensile strength of Imberg sandstone. For Neuhauser granite, the perfectly plastic case resulted in a stress of $14.9 \mathrm{MPa}$, and in the case of purely elastic strains, the maximum stress was $11.1 \mathrm{MPa}$. These values are distinctly higher than the results of the direct tension tests. For specimen with purely elastic material behaviour and constant cross section, the principal normal stresses are equal to the principal shear stresses in the case of pure torsional loading. Furthermore, the average normal stress is zero. Consequently, the calculated failure stresses for the purely elastic case using Eq. (10) can actually not be higher than the direct tensile strength, because the maximum shear stress and the maximum tensile stress are equal in this idealized case. The fracture pattern clearly shows that the failure in each test was caused by reaching the tensile strength, as expected for brittle materials. However, because of the different stiffness for tension and compression and the natural imperfections, concerning isotropy and homogeneity of the properties, related to rock material, an entire accordance between the calculated maximum shear stress and the tensile strength was not anticipated. For Imberg sandstone, the difference is less than 1.0 MPa and is, therefore, regarded as insignificant. Nevertheless, the direct tensile strength of Neuhauser granite is distinctly less than the calculated lower limit of the maximum shear stress. This observation has severe implications, because it means that the ultimate tensile stress during pure torsional loading was considerably higher than could be expected from the direct tension tests, although failure occurred clearly due to normal stresses. One explanation for these results might be found in the different petrographic natures of the two rock types. Imberg sandstone consists of minute grains embedded in a cemented matrix and can reasonably be treated as homogeneous and isotropic. In contrast, Neuhauser granite is a polycrystalline material, consisting of mineral grains connected at their grain boundaries. Each grain and each connection via a grain boundary have different properties. In the case of uniaxial tension, the weakest link fails, and due to the associated stress redistribution, other connections fail as well, leading finally to the ultimate failure of the sample. In contrast, the stress state during torsional loading is different, normal stresses and shear stresses are of equal magnitude, and shear stresses might relocate grains and therewith increase the overall resistance. The underlying mechanisms are expected to be similar to the effect of dislocation movement and accumulation on an atomic scale, what explains the increased resistance compared to uniaxial loading. This observation significantly affects also the results of the numerical simulation, since the constitutive equations cannot cover such effects correctly. As direct shear tests can actually not be applied to intact rock with considerable shear strength, the conducted torsion tests represent an alternative procedure to assess the shear behaviour of rock.

\subsection{Numerical Model}

The results of the numerical simulation had to very accurately reproduce the real rock mechanical behaviour in terms of stress-strain relations, damage, and failure. No mesh sensitivity in the results was permitted. These high 
requirements on the results of the numerical simulation demanded an appropriate numerical model and a suitable constitutive law. The CDP model, described in Chapter 2, is able to accurately simulate the behaviour of brittle materials due to tensile and compressive loading and was, therefore, the material model of choice. To improve the capabilities of the material model further, a subroutine was implemented with two major tasks. To implement the experimentally confirmed different stiffnesses in tension and compression, the first task was to evaluate for each element if the absolute value of the maximum principal stress is larger than the absolute value of the minimum principal stress. If this was true, the tensile secant modulus was assigned to the element and vice versa. The second task was to delete elements according to a certain deletion criterion. There were several reasons for deleting the elements. First, any type of destructive rock testing, regardless of whether uniaxial or triaxial compression test, direct or indirect tension test or torsion test results finally in the macroscopic fracture of the sample. Although this process could also be made visible by strain localization without deleting the elements, several disadvantages are associated therewith. Especially, for experiments dealing with violent failure, mostly because of tensile stresses, where the samples fail and the resistance to the applied moment or force drops instantaneously to zero. This behaviour can be simulated best by deleting the elements, because elements located in the strain localization area would still exhibit some resistance to the applied load and therewith associated extremely large plastic strains would occur. Furthermore, extremely distorted elements drastically decrease the computation speed, especially for the chosen explicit solution scheme. The size of the maximum stable time step depends on the dimensions of the smallest element. The smaller the characteristic length of the smallest element is, the smaller is the maximum stable time step. Element distortion reduces the characteristic length of an element additionally. Hence, the smaller the stable time step is, the more calculation steps have to be made and the longer the simulation takes. However, the results for simulations without deleting elements are also presented for the sake of comparison. The deletion criterion was based on two quantities, different for compression and tension: if the equivalent plastic strains and the principal stress exceeded a defined threshold value, the element was deleted. These values were determined from direct tension and uniaxial compression tests in two stages. The first stage was the subdivision of the total strains in elastic and inelastic strains at the peak value from the experimental stress-strain curves. The equivalent plastic strains were approximated via the inelastic strains and applied as starting values for the second stage, which was a reasonable procedure for a uniaxial stress state. Subsequently, the direct tensile and uniaxial compression tests were modelled and simulated, and the equivalent plastic strains for the deletion criterion were iteratively adopted until the resulting numerical and experimental stress-strain curve were nearly equal. The inelastic strains due to crack closure for the compression testing were not considered and the stress-strain curve was idealized as linear elastic in this region. The comparison of the numerical and experimental results for the direct tension test for Imberg sandstone and Neuhauser granite is illustrated in Fig. 11, where for the compression tests, the same excellent agreement was achieved. The mean value curve of the experimental results, displayed in Figs. 4 and 5 , was used as input parameters for the CDP model. The stress-strain curves for compressive loading were cutoff at the peak, although experimental values for the post-failure region were available. The reason for doing so was that the occurring compressive strains during the torsion tests were purely elastic because of the low stress level. Thus, only the linear-elastic constitutive equations prevail and
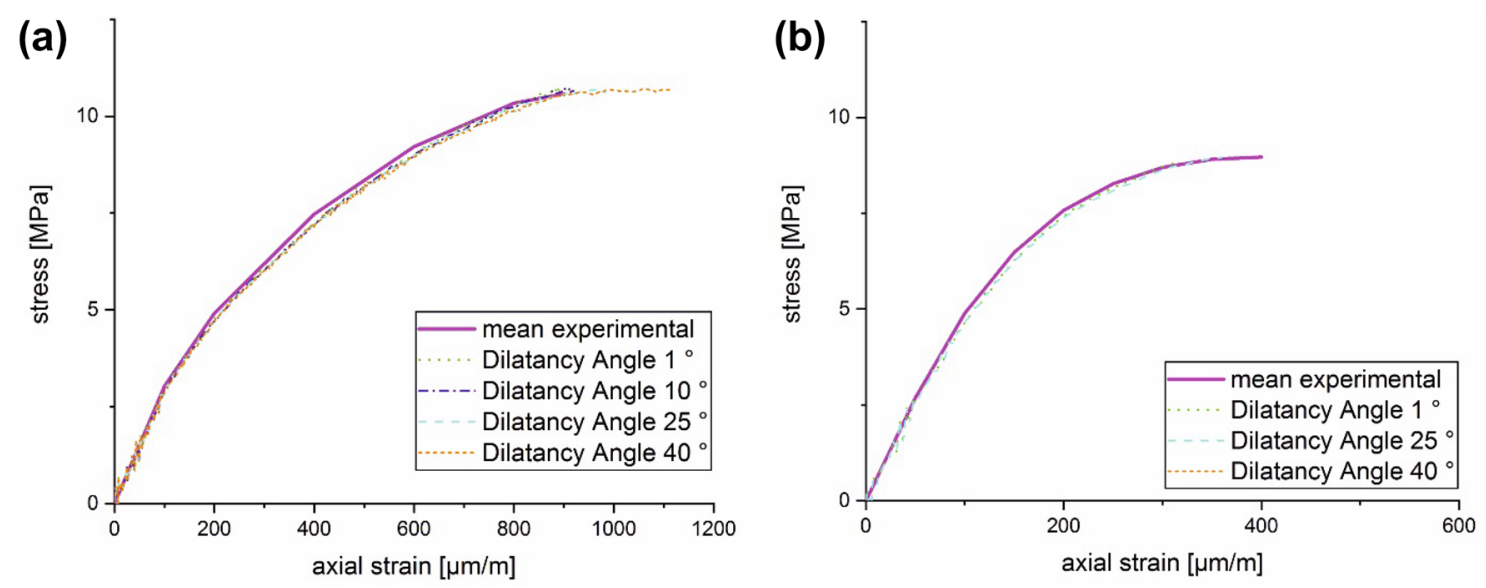

Fig. 11 Comparison of numerical and experimental results for direct tension test a Imberg sandstone and $\mathbf{b}$ Neuhauser granite 
no inelastic compressive strains occur. For the modelling of additional rock mechanical tasks, the compression postfailure behaviour can easily be incorporated.

Beside the stress-strain curves for tension and compression and the dilatancy angle, several other parameters were required for the material law, which were already described in Chapter 2 and are shown in Table 3. According to the results of experimental studies by Schickert and Winkler (1977) and Mills and Zimmerman (1970), $K_{\mathrm{c}}$ could be reasonably assumed to be constant with a value 0.667. Furthermore, as stated by Lubliner et al. (1989), the term in the yield function related to $K_{\mathrm{c}}$ vanishes for all stress states except for triaxial compression. Since none of the presented experiments exhibits triaxial compression, the value of $K_{\mathrm{c}}$ is completely irrelevant for the purpose of this paper. The ratio of equibiaxial-to-uniaxial compressive strength was estimated based on experiments conducted with concrete (Lubliner et al. 1989), granite (Yun et al. 2010), and sandstone (Maso and Lerau 1980), yielding an approximate range. However, by projecting the encountered stress states during the presented experiments on their approximate position at the yield surface in plane stress (red points in Fig. 1b), it becomes clear that the ratio of equibiaxial-to-uniaxial compressive strength does not significantly affect the current results, because the shape of the yield surface in this area is principally defined by the values for uniaxial compression and uniaxial tension. The eccentricity $\varepsilon$ controls by definition the dependency of the dilatancy angle on the confining pressure (Dassault Systèmes 2013). Since the hydrostatic stress component yields low values throughout the entire torsion test, no significant impact on the dilatancy angle was expected. Furthermore, for plane stress conditions as during the torsion tests, the volumetric plastic strains are only dependent on the dilatancy angle and not on the eccentricity. It can also be seen graphically from Fig. 1c) and mathematically from the formulation of the plastic potential that with increasing stress level, the contribution of the constant term below the square root in Eq. (4), containing the eccentricity, the tensile strength and the dilatancy angle, vanishes rapidly compared to the von Mises equivalent stress. Hence, no significant impact from the three parameters: $K_{\mathrm{c}}$, the ratio of equibiaxial-to-uniaxial compressive strength and the eccentricity $\varepsilon$ should be observed. To prove this hypothesis, numerical parameter studies with distinctly larger and smaller values than the chosen values were conducted for Imberg sandstone. The values are displayed in brackets in Table 3. No significant impact on the numerical results of the torsion tests was identified by the variation of these parameters, so the values found in the literature and default values were applied for all other simulation runs. In addition, the Poisson's ratio was varied and did not show any significant effect on the results as well. Nevertheless, the CDP model has the capabilities to simulate the evolution of the dilatancy angle and the plastic potential with confining pressure and damage because of the eccentricity $\varepsilon$ and the dependency of the occurring strains on the effective stress which incorporates the scalar damage variable. Indeed, for the purpose of the presented experiments, it is required to eliminate the influence of these parameters as far as possible to estimate the dilatancy angle for unconfined conditions without confounding effects and the torsion tests fulfil these requirements. Summarizing the current considerations shows that all needed input parameters for the CDP model can be derived from experiments, except for the eccentricity, where only approaches for an experimental determination exist (Jankowiak and Lodygowski 2005). The uniaxial stress-strain relations and the relation between inelastic strains and damage have to be provided in tabular form to the software. The scalar damage variable $D$ is defined according to Eq. (12) and can be determined, together with the elastic constants and the stress-strain relations, from compression and direct tension tests by conducting unloading-reloading cycles over the entire stress-strain curve and measure the variation of the secant modulus $E^{*}$ compared to the virgin secant modulus $E_{0}$, see Cieslik (2018). As already mentioned, the damage evaluation by this method is only possible for compressive loading at the moment. Values for $K_{\mathrm{c}}$ and the ratio of equibiaxial-to-uniaxial compressive strength can be either derived experimentally or reasonably estimated on the basis of available literature:

$D=1-\frac{E *}{E_{0}}$.

An explicit numerical solution scheme with a low value of Rayleigh stiffness proportional damping was

Table 3 Input parameters of Neuhauser granite and Imberg sandstone for the CDP model

\begin{tabular}{|c|c|c|c|c|c|c|c|}
\hline Rock type & Poisson's ratio & Density, $\mathrm{kg} / \mathrm{m}^{3}$ & $\begin{array}{l}\text { Secant modulus } \\
\text { compression, GPa }\end{array}$ & $\begin{array}{l}\text { Secant modulus } \\
\text { tension, GPa }\end{array}$ & Eccentricity & $\frac{\sigma_{b 0}}{\sigma_{c 0}}$ & $K_{\mathrm{c}}$ \\
\hline Neuhauser granite & 0.16 & 2650 & 62.0 & 54.0 & 0.1 & 1.12 & 0.667 \\
\hline Imberg sandstone & $\begin{array}{l}(0.08) \\
0.16 \\
(0.30)\end{array}$ & 2560 & 41.0 & 30.5 & $\begin{array}{l}(0.05) \\
0.1 \\
(0.5)\end{array}$ & $\begin{array}{l}(1.05) \\
1.12 \\
(1.25)\end{array}$ & $\begin{array}{l}(0.50) \\
0.667 \\
(0.80)\end{array}$ \\
\hline
\end{tabular}


used. To reduce the computation time, the loading rate was increased to $30 \%$, which is a common procedure in quasi-static simulations with an explicit solver. The critical loading rate was determined by performing simulations with various loading rates and define the value at which dynamic effects were introduced. Therefore, $30 \%$ was close to the maximum allowable loading rate without having significant dynamic effects. As an implicit assumption for the application of this procedure, the material must have no strain rate dependence. The numerical model is illustrated in Fig. 13 and consists of about 72,000 eightnode brick elements with reduced integration. The mesh size in the middle section of the rock sample is $1.0 \mathrm{~mm}$ and $1.8 \mathrm{~mm}$ at the end section. Besides the rock sample, the collet chucks were modelled as continuum elements. Various simulation runs were performed to investigate if the compressive loading during the tensioning of the collet chucks had a significant influence on the results. Therefore, a friction contact formulation was modelled between the collet chucks and the rock specimen; subsequently, different radial loads were applied on the outside of the collet chucks. No significant influence on the numerical results was observed; hence, the more efficient solution was chosen to use a tie connection between the collet chucks and the rock sample without radial loads. The residual boundary conditions were applied to the collet chucks, representing the real situation with one fixed and one floating bearing. The distortion of the sample was applied via the fixed bearing. The circumferential nodes at the end positions of the strain gauges and the video extensometers were stored as node sets. The axial displacement of all nodes of each node set was averaged and the difference in axial displacement between the two node sets was calculated and divided by the axial distance between the two node sets to obtain the axial strains. This procedure was obviously conducted separately for the strain gauge measurement and for the video extensometer measurement. In Fig. 13, the two node sets for the evaluation of the video extensometer measurement are highlighted.

\subsection{Results}

The results of the numerical simulation for Imberg sandstone and Neuhauser granite are illustrated in Fig. 12. For comparison with the experiments, the strain gauge measurements were used, where only the experimental mean value curves were linearized in sections. In Fig. 13, the numerical model is shown after the sample failed in the simulation. The real fracture behaviour was reproduced in the simulation and the qualitative agreement was high. The following facts should be recalled: The major input parameters were experimentally determined stress-strain curves for uniaxial compression and tension and the deletion criterion is based
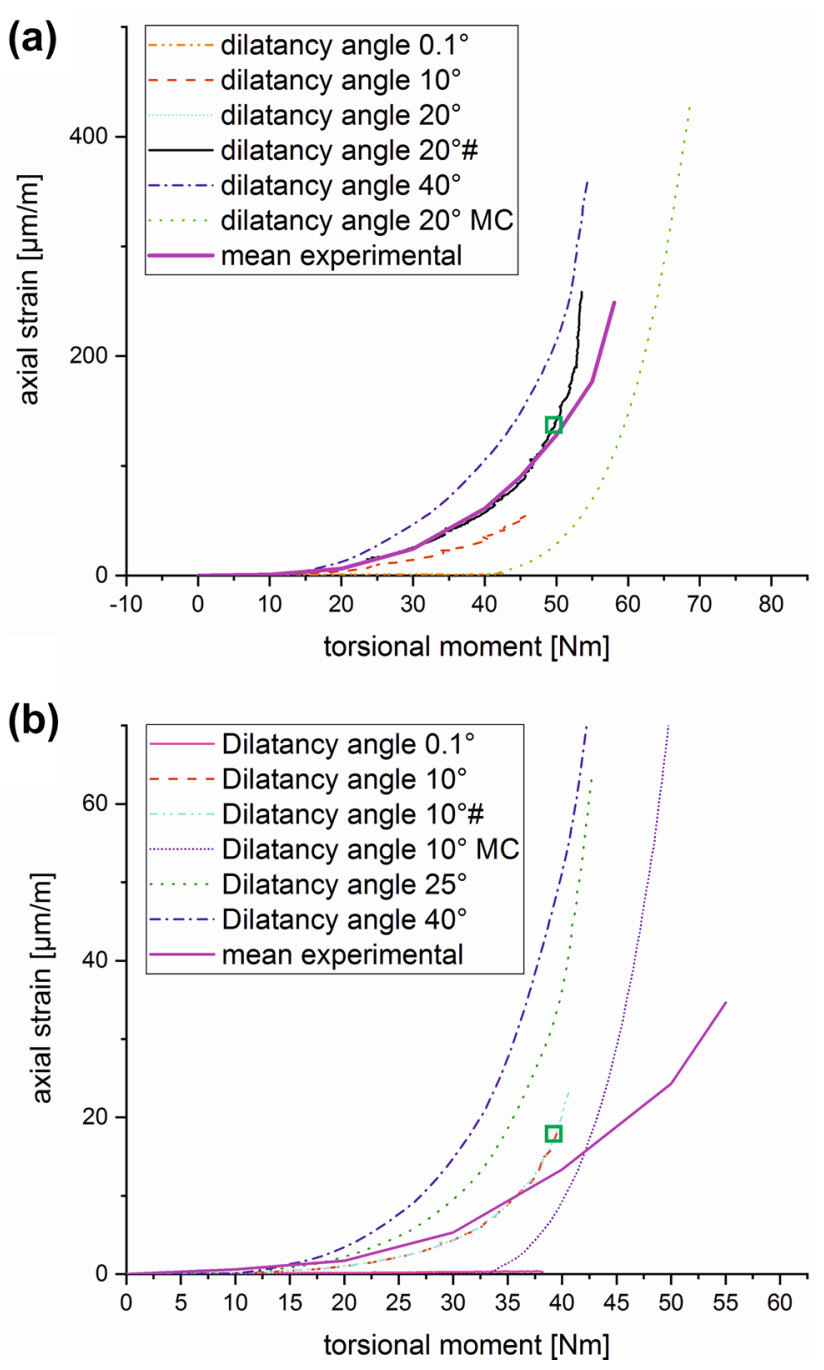

Fig. 12 Comparison of numerical and experimental results for the torsion tests a Imberg sandstone and $\mathbf{b}$ Neuhauser granite. The green rectangles mark the end of the curve with element deletion. The suffix \# means without element deletion and the suffix MC means MohrCoulomb plasticity model

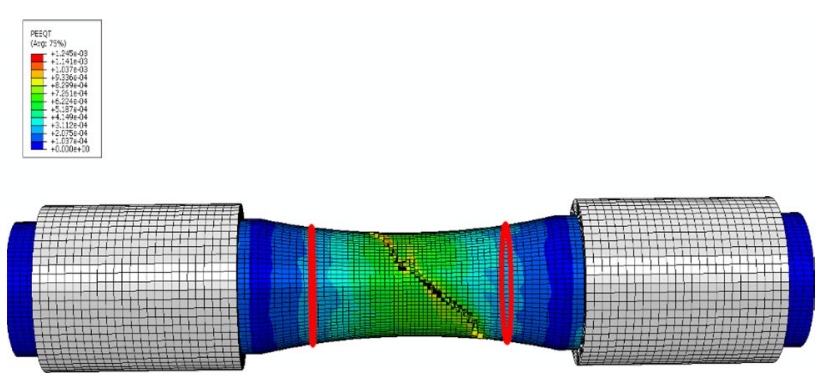

Fig. 13 Numerical model at the end of the simulation with the nodes at the position of video extensometer measurement marked 
on the occurring equivalent plastic strains in combination with the uniaxial tensile strength, respectively, the uniaxial compressive strength. The onset of plastic strains, recognizable by the over-proportional onset of axial strains in Fig. 12, occurred as expected at exactly the same stress level as in the direct tension tests. For Imberg sandstone, the numerical results for a dilatancy angle $\psi_{\mathrm{CDP}}$ of $20^{\circ}$ are in good agreement with the experimental results. As described in Chapter 2.1, the dilatancy angles derived from the inverse determination of the CDP model needed to be adapted to the common definition by Eq. (6). Hence, a value of $20^{\circ}$ for $\psi_{\mathrm{CDP}}$ equals $14^{\circ}$ for $\psi$. The curve for the simulation without element deletion exhibits the best conformity over the entire range of the torsional moment vs. axial strain curve. Thus, regarding the estimation of the dilatancy angle, no element deletion procedure was required. However, for the purpose of simulating the macroscopic fracture behaviour of rock, for various types of loading, this procedure still is an interesting option. Although the results reveal that the deletion criteria have potential for improvement. Recalling that the deletion criteria were based on experimental results and that direct tension tests and unconfined compression tests could be simulated very accurately, the slight error is accepted for the torsion tests. The maximum torsional moment for the numerical simulation was $51.3 \mathrm{Nm}$, compared to $56.8 \mathrm{Nm}$ from the experiments. It is not the purpose of this article to determine the dilatancy angle accurate to a degree, which is actually not possible with the presented method, rather a reasonable estimation of the range of the dilatancy angle should be provided and the torsional moment vs. axial strain curves should have a similar shape. With the proposed novel setup, confounding effects such as inelastic strains due to axial cracking were avoided and the determined dilatancy angle $\psi$ with values in the range of $14^{\circ} \pm 4^{\circ}$ is in the same order of magnitude as the values given by Vermeer and De Borst (1984) for rock. Although the authors are aware of the fact that the dilatancy angle does not have a constant value, the good agreement between the numerical and experimental results with a reasonable dilatancy angle indicated that the current approach was sufficient, at least until failure. For the sake of comparison, simulations were conducted using a Mohr-Coulomb plasticity model, implemented in the finite-element software Abaqus 6.13. The applied input parameters were determined experimentally by uniaxial and triaxial compression tests and direct tension tests, and are summarized in Table 4. For both rock types, the qualitatively different results in the form of the torsional moment vs. axial strain curves are clearly observable. The onset of axial strains required much higher torsional moments than detected in the experiments or by the simulations with the CDP model. The reason for that is the larger initial elastic region in the $3 \mathrm{D}$ stress space and the mainly shear stressdependent flow rule.

An even more important conclusion could be drawn from the results of simulations with Neuhauser granite. The torsional moment vs. axial strain curve from the numerical simulation and the experiments showed a significant deviation for any dilatancy angle, mostly due to the different maximum torsional moment. Neither the simulations with the CDP model nor with the Mohr-Coulomb plasticity model could achieve a satisfactory result. This observation is in accordance with the fact that Imberg sandstone and Neuhauser granite yielded nearly the same maximum torsional moment during the torsion experiments, while the direct tensile strength of Imberg sandstone was distinctly higher than the direct tensile strength of Neuhauser granite. Hence, the numerical results were consistent with the provided input parameters, particularly concerning the stress-strain curve for tension. From the type and characteristic of rupture during the experiments, failure was clearly associated with reaching the normal stress threshold value, which should be the tensile strength, for both types of rock. For Imberg sandstone, the entire results from numerical simulation to various types of experiments were consistent and proved the applied theoretical framework. An explanation for these observations could be found in the obvious difference between the two rock types in grain size and the type of bonding. Imberg sandstone consists of small, angular grains in a properly cemented matrix without any pores, yielding very homogenous properties. Therefore, Imberg sandstone reliably could be treated as continuum with the given geometry. In contrast, Neuhauser granite can be characterized as a polycrystalline material, consisting of different mineral grains connected at their boundaries. In accordance with the definitions and findings described by Gross and Seelig (2017) polycrystalline materials may exhibit locking effects of the individual grains because of the shear stresses occurring during torsional loading. This effect might have caused

Table 4 Input parameters for the Mohr-Coulomb plasticity model

\begin{tabular}{|c|c|c|c|c|c|c|c|}
\hline Rock type & Poisson's ratio & Density, $\mathrm{kg} / \mathrm{m}^{3}$ & $\begin{array}{l}\text { Secant modu- } \\
\text { lus, GPa }\end{array}$ & Friction angle $^{\circ}$ & $\begin{array}{l}\text { Dilatancy } \\
\text { angle, }^{\circ}\end{array}$ & Cohesion, $\mathrm{MPa}$ & $\begin{array}{l}\text { Tension } \\
\text { Cutoff, } \\
\text { MPa }\end{array}$ \\
\hline Neuhauser granite & 0.16 & 2650 & 62.0 & 56.8 & 10.0 & 21.5 & 8.8 \\
\hline Imberg sandstone & 0.16 & 2560 & 41.0 & 52.4 & 20.0 & 26.1 & 10.6 \\
\hline
\end{tabular}


the increased torsion resistance and reduced axial strains of the granite samples. This effect was not relevant for the direct tensile test due to pure axial loading and was not observed for Imberg sandstone for obvious reasons. These findings were already addressed in Chapter 3.3.2 and are now recovered for the numerical simulation. Consequently, the behaviour of Neuhauser granite, and crystalline rocks in general, due to different loading situations could not be described correctly with the current continuum mechanics approach. An effect which might also have bearing on the results is the ratio of loaded volume to maximum grain size. This criterion is actually well known, but a ratio of 10:1 for minimum diameter to maximum grain size as in the current case is normally assumed to be adequate. These observations also coincide with the findings of a common theory for the fracture of quasi-brittle materials, originated by Weibull (Gross and Seelig 2017). Certainly, the calculation of the effective volume for the non-uniaxial stress situation is complex, an analysis according to this probabilistic concept requires a large number of experimental results and the applicability for granitic material is questionable (Todinov 2008). However, the current results emphasize the need to carefully evaluate experiments with crystalline rocks in combination with primary shear stresses. A dilatancy angle cannot be assigned to Neuhauser granite reliably from the current data. Nevertheless, the extremely low measured axial strains and the steep slope at the beginning indicate a low dilatancy angle $\psi$. Clearly, the large difference in occurring axial strains for a dilatancy angle of $10^{\circ}, 25^{\circ}$, or $40^{\circ}$ is visible in Fig. 12.

\subsection{Compression Tests}

The purpose of the compression tests was not only to determine the elastic constants and the unconfined compressive strength, but also to derive scalar damage values as input parameters for the CDP model. For that reason, the tests were conducted via circumferential strain control, measured with a circumferential extensometer, and by applying unloading and reloading loops along the entire stress-strain curve, as suggested by the ISRM methods. The axial strains were measured with two extensometers directly on the specimen and also via the piston displacement over the complete specimen length. After measuring the stiffness degradation, the scalar damage variable $D$ was calculated using Eq. (12). Damage was only calculated beyond the crack damage stress in accordance with the research of Martin and Chandler (1994). Since the overall stress level during the torsion tests was below $20 \%$ of the unconfined compressive strength, rock failure or damage due to compressive stresses was irrelevant for these experiments. However, the results of the unconfined compression tests were used to determine the dilatancy angle $\psi$ with common methods, as described, e.g., in Walton and Diederichs (2015). The tests were conducted with Neuhauser granite and Imberg sandstone. The undamaged secant modulus was principally determined from measurements in the region below the crack damage stress and above the lower bound of the elastic region. The unloading-reloading loops were performed in more or less regular intervals, starting directly at the peak load. The results of the experiments and the damage evolution in particular, calculated via Eq. (12), are illustrated in Fig. 14 for Neuhauser granite. The axial stress is plotted on the ordinate normalized by the UCS and the axial strain $\varepsilon_{\text {axial }}$ is plotted on the abscissa, normalized by the axial strain at maximum stress $\varepsilon_{\text {axial,crit }}$. This form of presentation was chosen to allow a consistent evaluation and to show that though the particular experiments yielded different values for the UCS at different critical strains, the normalized curves are very similar, proving that the determined damage values for the post-failure region
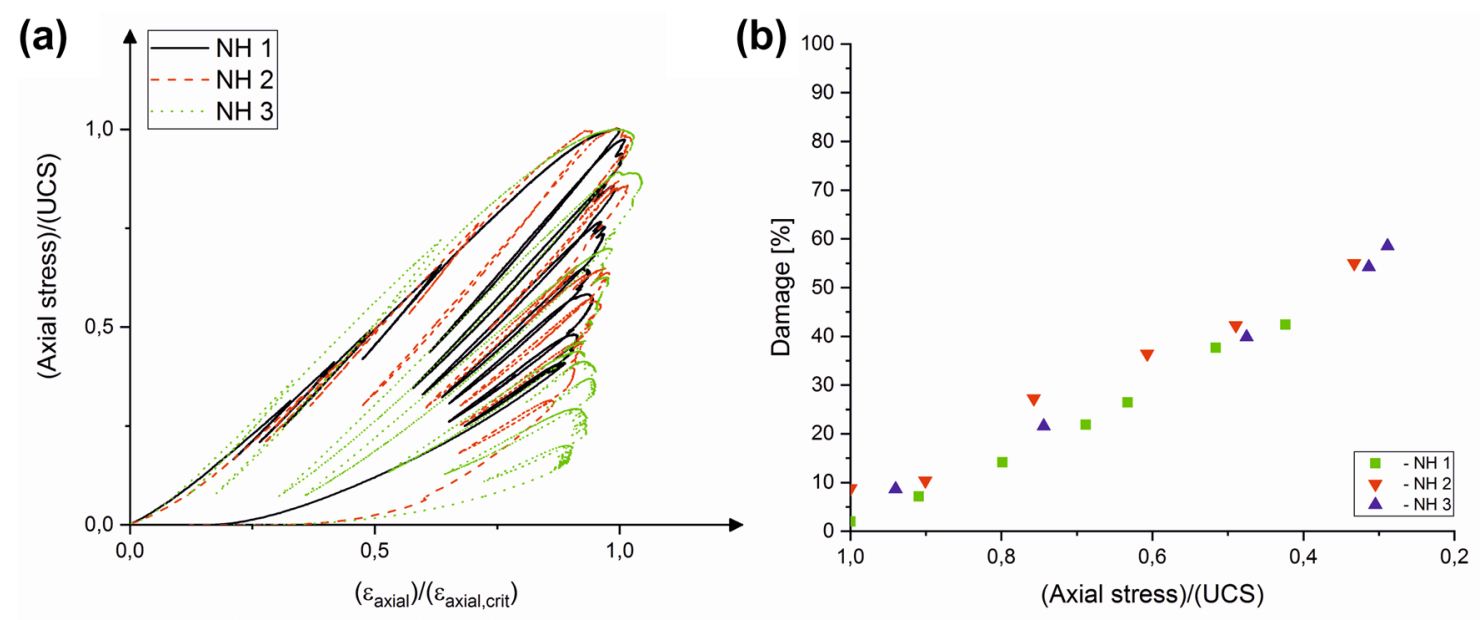

Fig. 14 Normalized stress-strain curves (a) and damage evolution (b) for Neuhauser granite 
are pervasive material properties. For the damage evolution, the normalized axial stress was plotted on the abscissa, because actually, all tested rock types exhibited class 2 or intermediate behaviour between class 1 and class 2 . Thus, a plastic or inelastic strain-based form of presentation would have resulted in a meaningless figure. This circumstance can also be an issue for the implementation of the post-failure behaviour in the constitutive model. By measuring the circumferential strains and the axial strains, the volumetric strains can be calculated as the sum of the axial strains and twice the circumferential strains. Certainly, the measurement of the occurring strains with extensometers or strain gauges directly at the specimen in the post-failure region is inaccurate due to slabbing/splitting and bifurcation, resulting in the separation of the specimen into two or more rigid bodies. In triaxial compression testing, the volumetric strains are often directly measured via the amount of fluid displaced from the cell, thus enabling a more reliable calculation of the relatively insensitive ratio of the increments of plastic volumetric strains $\varepsilon_{\mathrm{vp}}$ to the plastic axial strains $\varepsilon_{1 \mathrm{p}}$, required to calculate the dilatancy angle. For unconfined compression testing, the described procedure is usually not available. However, for the sake of comparison with the results of the torsion tests and with the limitation to specimens without macroscopic strain localization and without significant slabbing/splitting, the inelastic strain components could be computed by subtracting the elastic strain components from the total measured strains. Although not correct, these inelastic strains were treated as fully plastic strains, as has also been done by other researchers. For the calculation of the elastic strains, simply Hooke's law was used. The dilatancy angle $\psi$ is then calculated according to Eq. (3). The average value for the calculated dilatancy angle for Neuhauser granite is $62^{\circ}$ and for Imberg sandstone $49^{\circ}$. Hence, the difference between the results from compression tests and torsion tests is significant, for granite even more than for Imberg sandstone. According to Vermeer and De Borst (1984), the maximum possible dilatancy angle from a physical point of view is limited by the friction angle. Following the work of Martin and Chandler (1994), the peak friction angle is reached at low damage, so at the peak of the stress-strain curve is a reasonable assumption. The friction angles were determined by compression tests with $0.0,1.0$, and $2.5 \mathrm{MPa}$ confining pressure for both rock types. The determined friction angles were directly used in the Mohr-Coulomb plasticity model and are shown in Table 4 . Hence, $62^{\circ}$ for the dilatancy angle is already higher than the calculated friction angle of $56.8^{\circ}$, but incorporating the uncertainties related with the determination of the maximum friction angle, it might be a theoretically possible value. However, if a constant dilatancy angle of around $50^{\circ}$ would be used for the simulation of the torsion tests with Imberg sandstone, the results would yield a low conformity with the experimental results, independent of the applied constitutive model. Although acknowledging the dependence of the dilatancy angles on the strain history and the shortcomings of the proposed procedure, the current results indicate that the dilatancy angle up to the ultimate stress level might be reasonably assumed by the common rule of thumb that the dilatancy angle is around $20^{\circ}-30^{\circ}$ less than the friction angle. This is an important conclusion considering that dilatancy angles of $80^{\circ}$ or even higher have been reported.

\section{Conclusion and Discussion}

Two alternative, respectively, improved rock-testing methods were presented in this article. Torsion tests were successfully performed with crystalline and sedimentary rock. Sample geometry and testing procedure were based on the experience from metal and plastic testing, but were optimized to the current purpose. However, the data interpretation and conclusions were completely different. The torsional loading resulted in a state of plane stress of pure shear, which is desired for the investigation of the dilation behaviour according to Vermeer and De Borst (1984). Due to the low overall stress level with maximum normal stresses below $20 \mathrm{MPa}$ and the special type of pure torsional loading, no confounding effects from axial cracking or crack closure were detected. Hence, the occurring axial strains were directly dependent on the magnitude of the dilatancy angle. These initially theoretical considerations were confirmed by experiments and numerical simulations. An inverse determination procedure was applied to estimate the dilatancy angle, which yielded reasonable results. Nevertheless, it was not the purpose to exactly quantify the dilatancy angle, rather the magnitude should be found and the relevant qualitative behaviour should be modelled correctly. The presented concept is neither able nor intended to replace the existing methods, using triaxial compression tests. However, additional information could be gained, especially for the case of unconfined conditions.

For simulation purposes, the concrete damaged plasticity model for brittle materials was used. Reliably determined stress-strain curves for uniaxial tensile and compressive loading were required as input parameters. While robust and approved procedures are available for compression testing, the situation is very different for tensile loading. Samples often fail invalidly during testing before reaching the true tensile strength, either due to poor preparation or the impact of undesired bending and torsional loading. To avoid the negative influence of clamping on the results and to force the strain localization to take place in the middle of the sample, a novel clamping device was developed and combined with an improved hourglass-shaped sample geometry. The test series on sedimentary and crystalline rock yielded accurate 
and repeatable results and the strains were measured at the location of maximum stress, which is not necessarily the case for cylindrical-shaped samples. The new clamping device was operated purely mechanically and enabled a bending and torsional moment-free loading of the sample. Furthermore, the exchange of rock samples between two tests runs was done easily and quickly, and the process of gluing the specimen in metal caps was omitted, eliminating another potential source of error. Admittedly, the temporal and monetary effort for the specimen preparation was larger than for cylindrical-shaped samples. However, besides the already described advantages, the presented test setup might even allow the derivation of the stress-strain curve for the post-peak region, by modifying the test control to a strain gauge-based system with the use of a high dynamic measurement amplifier.

Comparing the results of the numerical and experimental investigations for the torsion and the direct tension tests yielded some important conclusions. For Imberg sandstone, the strains could be measured accurately with any type of measurement system and the experimental and numerical results were consistent for every type of loading. By applying the proposed inverse determination procedure, a reasonable range for the dilatancy angle of $14^{\circ} \pm 4^{\circ}$ was identified. Hence, the common rule of thumb that the dilatancy angle is $20^{\circ}-30^{\circ}$ less than the friction angle appears to be an appropriate first estimation. The numerical simulation revealed also that a dilatancy angle greater than $40^{\circ}$ is not very realistic for the tested sandstone for unconfined conditions, while determination with established procedures yields an average dilatancy angle close to the friction angle of $52^{\circ}$. However, a general disagreement between the numerical and experimental results for the torsion tests was observed for Neuhauser granite. An apparently increased resistance to tensile normal stresses compared to uniaxial tensile loading was found. The polycrystalline structure of the granite, consisting of mineral grains connected at their grain boundaries was identified as possible source for the discrepancy. In contrast to uniaxial loading in direct tension tests, the stress state during torsional loading was different, normal stresses and shear stresses were of equal magnitude and shear stresses probably have relocated grains and therewith increased the overall resistance. The underlying mechanisms were expected to be similar to the effect of dislocation movement and accumulation on the atomic scale. Nevertheless, common constitutive models for geomaterials are not capable of simulating such effects. Therefore, no adequate conformity between numerical and experimental results could be found and no dilatancy angle could be assigned. These observations demonstrate that the behaviour of crystalline rocks could be different from that expected from tension or compression tests, particularly if the ratio of shear stresses to normal stresses is as high as in the torsion tests. As direct shear tests can actually not be applied to rock with considerable shear strength, the conducted torsion tests represent an alternative procedure to assess the shear behaviour of intact rock.

Acknowledgements Open access funding provided by Montanuniversität Leoben. We are very thankful to Peter Moharitsch for designing and manufacturing the novel clamping device. Furthermore, the vital assistance of Dr. Gerhard Winter when conducting the torsion experiments is highly appreciated. We also want to thank Sandvik Mining and Construction G.m.b.H for the fruitful cooperation and the financial support.

\section{Compliance with Ethical Standards}

Conflict of interest The authors declare that there is no conflict of interest.

Open Access This article is distributed under the terms of the Creative Commons Attribution 4.0 International License (http://creativeco mmons.org/licenses/by/4.0/), which permits unrestricted use, distribution, and reproduction in any medium, provided you give appropriate credit to the original author(s) and the source, provide a link to the Creative Commons license, and indicate if changes were made.

\section{References}

Alejano LR, Alonso E (2005) Considerations of the dilatancy angle in rocks and rock masses. Int J Rock Mech Min Sci 42:481-507. https://doi.org/10.1016/j.ijrmms.2005.01.003

Arzúa J, Alejano LR (2013) Dilation in granite during servo-controlled triaxial strength tests. Int J Rock Mech Min Sci 61:43-56. https:// doi.org/10.1016/j.ijrmms.2013.02.007

Bazant ZP (1976) Instability, ductility and size effect in strain softening concrete. J Eng Mech Div 102(2):331-344

Bieniawski ZT, Hawkes I (2007) Suggested methods for determining tensile strength of rock materials. In: The complete ISRM suggested methods for rock characterization. Testing and monitoring: 1974-2006, compilation arranged by the ISRM Turkish National Group. Kozan Ofset, Ankara

Blümel M (2000) Improved procedures for laboratory rock testing. In: EUROCK, nationales symposium für Felsmechanik und Tunnelbau, vol 14, pp 573-578

Bolton MD (1986) The strength and dilatancy of sands. Geotechnique 36(1):65-78. https://doi.org/10.1680/geot.1986.36.1.65

Brace WF et al (1966) Dilatancy in the fracture of crystalline rocks. J Geophys Res 71:16

Broch E, Franklin JA (1972) The point load strength test. Int J Rock Mech Min Sci 9:669-697

Cieslik J (2018) Dilatancy as a measure of fracturing development in the process of rock damage. Open Geosci 10:484-490

Cook NGW (1970) An experiment providing that dilatancy is a pervasive volumetric property of brittle rock loaded to failure. Rock Mech 2:181-188

Dassault Systèmes (2013) Concrete damaged plasticity In: Abaqus 6.13 analysis user's guide, vol. III: materials, Providence, RI, USA

Fairhurst CE, Hudson JA (1999) Draft ISRM suggested method for the complete stress-strain curve for intact rock in uniaxial compression. Int J Rock Mech Min Sci 36:279-289

Franklin JA, Dusseault MB (1989) Rock engineering. McGraw-Hill, New York City 
Garner NE (1961) The photoelastic determination of the stress distribution caused by a bit tooth on an indexed surface, Master thesis, University of Texas

Gerstle KB, Zimmerman RM, Winkler HD, Traina LA, Taylor MA, Schickert G, Rossi P, Newman JB, Linse D, Ko HY, Kotsovos MD, Bertacchi P, Bellotti R, Aschl H (1980) Behavior of concrete under multiaxial stress states. J Eng Mech Div 106:1383-1403

Gorski B, Conlon B, Ljunggren B (2007) Forsmark Site investigationDetermination of the direct and indirect tensile strength on cores from borehole KFM01D. SKB P-07-76, Svensk ärnbränslehantering $\mathrm{AB}$, Stockholm

Gross D, Seelig T (2017) Fracture mechanics-with an introduction to micromechanics, 3rd edn. Springer, Berlin

Grosvenor NE (1961) A new method for determining the tensile strength of a rock. Am Inst Min Met Petrol Eng 220:447-449

Haimson BC (1968) Hydraulic fracturing in porous and non-porous rock and its potential for determining in situ stress at great depth, Dissertation, University of Minnesota

Haimson BC, Tharp TM (1974) Stresses around boreholes in bilinear elastic rock. Soc Pet Eng. https://doi.org/10.2118/4241-pa

Hawkes I, Mellor M (1969) Uniaxial testing in rock mechanics laboratories. Eng Geol 4:179-285. https://doi.org/10.1016/00137952(70)90034-7

Hibbeler RC (2006) Mechanics of materials, 8th edn. Person Prentice Hall, Upper Saddle River, p 239

Hillerborg A (1985) Numerical methods to simulate softening and fracture of concrete. Eng Appl Fract Mech Book Ser 4:141-170. https://doi.org/10.1007/978-94-009-6152-4_3

Hoek E (1964) Fracture of anisotropic rock. J S Afr Inst Min Metall 64:501-518

Hubbert MK, Willis DG (1957) Mechanics of hydraulic fracturing. Pet Trans AIME 210:153-168

Jankowiak T, Lodygowski T (2005) Identification of parameters of concrete damage plasticity constitutive model. Found Civ Env Eng 6(1):53-69

Jiang J-F, Wu Y-F (2012) Identification of material parameters for Drucker-Prager plasticity model for FRP confined circular concrete columns. Int J Solids Struct 49:445-456

Lee J, Fenves GL (1998) Plastic-damage model for cyclic loading of concrete structures. J Eng Mech 124:892-900. https://doi. org/10.1061/(ASCE)0733-9399(1998)124:8(892)

Lubliner J et al (1989) A plasticity model for concrete. Int J Solids Struct 25:3. https://doi.org/10.1016/0020-7683(89)90050-4

Martin CD, Chandler NA (1994) The progressive fracture of Lac du bonnet granite. Int J Rock Mech Min Sci Geomech Abstr 31:6. https://doi.org/10.1016/0148-9062(94)90005-1

Maso JC, Lerau J (1980) Mechanical behaviour of Darney Sandstone (Vosges, France) in biaxial compression. Int J Rock Mech Min Sci Geomech Abstr 17:109-115

Mellor M, Hawkes I (1971) Measurement of tensile strength by diametral compression of discs and annuli. Eng Geol 5:173-225. https://doi.org/10.1016/0013-7952(71)90001-9

Mills LL, Zimmerman RM (1970) Compressive strength of plain concrete under multiaxial loading conditions. J Am Conc Inst 67:802-807

Missouri Highway and Transport Department (1981) Evaluation of the point load test for rock. In: Missouri cooperative highway research program final report study, pp 79-2

Moradian M, Shekarchi M (2016) Durability and dimensional stability of steel fiber reinforced cementitious mortar in comparison to high performance concrete. Asian J Civ Eng 174:515-535

Obert L, Windes SL, Duvall WI (1946) Standardized tests for determining the physical properties of mine rock. U.S. Bureau of Mines, R.I. 3891
Paterson MS, Olgaard DL (2000) Rock deformation tests to large shear strains in torsion. J Struct Geol 22:1341-1358. https:// doi.org/10.1016/s0191-8141(00)00042-0

Perras MA, Diederichs MS (2014) A review of the tensile strength of rock: concepts and Testing. Geotech Geol Eng 32:525-546

Reynolds O (1885) On the dilatancy of media composed of rigid particles in contact. In: The London, Edingburgh and Dublin Philosophical Magazine and Journal of Science, 5th Series

Roscoe KH (1970) The influence of strains in soil mechanics. Geotechnique 20:2. https://doi.org/10.1680/geot.1970.20.2.129

Rowe PW (1962) The stress-dilatancy relation for static equilibrium of an assembly of particles in contact. Proc R Soc Lond Ser A Math Phys Sci 269:1339. https://doi.org/10.1098/ rspa.1962.0193

Rowe PW (1972) Theoretical meaning and observed values of deformation parameters for soil. In: Proc. Roscoe Memorial Symp. on stress-strain behaviour of soils, Cambridge, pp 143-194

Rudnicki JW, Rice JR (1975) Conditions of the localization of the deformation in pressure sensitive materials. J Mech Phys Solids 23:6. https://doi.org/10.1016/0022-5096(75)90001-0

Rummel F, Fairhurst C (1970) Determination of the post-failure behavior of brittle rock using a servo-controlled testing machine. Rock Mech 2:4. https://doi.org/10.1007/BF01245574

Schickert G, Winkler H (1977) Results of test concerning strength and strain of concerte subjected to multiaxial compressive stresses. Ger Comm Reinforced Conc, Heft, p 277

Singh B (1974) Reliability of dilatometer tests in the determination of the modulus of deformation of a jointed rock mass. In: Field testing and instrumentation of rock, American society for testing and materials, pp 52-72

Stimpson B, Chen R (1993) Measurement of rock elastic moduli in tension and in compression and its practical significance. Can Geotech J 30(2):338-347

Sundaram PN, Corrales JM (1980) Brazilian tensile strength of rocks with different elastic properties in tension and compression. Int J Rock Mech Min Sci Geomech Abstr 17:2

Todinov MT (2008) Is Weibull distribution the correct model for predicting probability of failure initiated by non-interacting flaws? Int J Solids Struct 46(3-4):887-901. https://doi.org/10.1016/j. ijsolstr.2008.09.033

Vermeer PA, De Borst R (1984) Non-associated plasticity for soils concrete and rock. Heron 29(1987):3. https://doi. org/10.1007/978-94-017-2653-5_10

Walton G, Diederichs MS (2015) A new model for the dilation of brittle rocks based on laboratory compression test data with separate treatment of dilatancy mobilization and decay. Geotech Geol Eng 33:661-679. https://doi.org/10.1007/s1070 6-015-9849-9

Walton G, Diederichs MS, Arzúa J (2014) A detailed look at prepeak dilatancy in a granite-determining "plastic" strains from laboratory test data. Rock Eng Rock Mech Struct In On Rock Mass EUROCK 2014. https://doi.org/10.1201/b16955-33

Walton G, Arzúa J, Alejano LR et al (2015) A laboratory-testingbased study on the strength, deformability, and dilatancy of carbonate rocks at low confinement. Rock Mech Rock Eng 48:941. https://doi.org/10.1007/s00603-014-0631-8

Wawersik WR, Brace WF (1970) Post-failure behaviour of a granite and diabase. Rock Mech 3:2. https://doi.org/10.1007/BF012 39627

Wawersik WR, Fairhurst C (1969) A study of brittle rock fracture in laboratory compression experiments. Int J Rock Mech Min Sci Geomech Abstr 7:5. https://doi.org/10.1016/01489062(70)90007-0

Yoshitake I, Rajabipour F, Mimura Y, Scanlon A (2012) A prediction method of tensile Young's modulus of concrete at early age. 
Adv Civ Eng 2012:391214. https://doi.org/10.1155/2012/39121 4

Yu X, da Gama CD, Na Y, Wang Q, Xie Q (2005) Deformation behaviour of rocks under compression and direct tension. J South Afr Inst Min Metall 105:55-62

Yun X, Mitri H, Yang X, Wang Y (2010) Experimental investigation into biaxial compressive strength of granite. Int J Rock Mech Min Sci 2(47):334-341. https://doi.org/10.1016/j.ijrmm s.2009.11.004

Zarroug NM, Padmanabhan R, MacDonald BJ, Young P, Hashmi MSJ (2003) Mild steel (En8) rod tests under combined tensiontorsion loading. J Mater Process Technol 143-144:807-813. https://doi.org/10.1016/S0924-0136(03)00362-5
Zhao XG, Cai M (2010) A mobilized dilation angle model for rocks. Int J Rock Mech Min Sci 47:368-384. https://doi.org/10.1016/j. ijrmms.2009.12.007

Zoback MD, Rummel F, Jung R, Raleigh CB (1977) Laboratory hydraulic fracturing experiments in intact and pre-fractured rock. Int J Rock Mech Min Sci Geomech Abstr 14:2. https:// doi.org/10.1016/0148-9062(77)90196-6

Publisher's Note Springer Nature remains neutral with regard to jurisdictional claims in published maps and institutional affiliations. 